\title{
Effect of iron(III) salts on steel corrosion in acid solutions. A review ${ }^{1}$
}

\author{
Ya.G. Avdeev ${ }^{10} *$ and Yu.I. Kuznetsov \\ A.N. Frumkin Institute of Physical Chemistry and Electrochemistry, Russian Academy \\ of Sciences, Leninskii pr. 31, 119071 Moscow, Russian Federation \\ *E-mail: avdeevavdeev@mail.ru
}

\begin{abstract}
Data on the specific features of the corrosion of steels in acid solutions containing Fe(III) salts are summarized. The current state of studies in the field of their protection in these media using corrosion inhibitors (CI) is analyzed. The main routes by which Fe(III) salts enter acid solutions are considered. Most often, they enter a corrosive environment upon dissolution of oxide scale in the acids. The corrosion of low-carbon steels in acid solutions containing Fe(III) salts results from three partial reactions: anodic ionization of iron; cathodic reduction of protons and $\mathrm{Fe}$ (III) cations. The first two reactions occur under kinetic control, and the last one, under diffusion control. The presence of Fe(III) salts in acid solutions often significantly accelerates the corrosion of steels due to predominant hindrance of the cathodic reaction by Fe(III) cations. As a rule, $\mathrm{Fe}$ (III) cations significantly reduce the protective effect of CIs of steels added to acid etching solutions. The protective effect of CIs in acid solutions containing Fe(III) salts can be increased by reducing the overall corrosivity of the medium. This can be achieved by addition of $\mathrm{H}_{3} \mathrm{PO}_{4}$ that can bind $\mathrm{Fe}(\mathrm{III})$ into strong complexes that have lower oxidizing capacity than $\mathrm{Fe}$ (III) aqua complexes and mobility in the corrosive environment characterized by the diffusion coefficient. A decrease in the mobility of Fe(III) cations is extremely important for slowing down their reduction, which occurs in the diffusion mode, by the CI. A CI used in a corrosive environment should be efficient not only in slowing down the cathodic reduction of protons and anodic ionization of iron, but should also significantly suppress the reduction of $\mathrm{Fe}(\mathrm{III})$ cations that occurs under diffusion control. These requirements are satisfied by $\mathrm{H}_{2} \mathrm{SO}_{4}+\mathrm{H}_{3} \mathrm{PO}_{4}$ and $\mathrm{HCl}+\mathrm{H}_{3} \mathrm{PO}_{4}$ solutions containing $\mathrm{Fe}(\mathrm{III})$ salts and inhibited by a three-component formulation of a substituted 1,2,4-triazole (IFKhAN-92 corrosion inhibitor) + KNCS + urotropine. It is shown that the efficiency of this formulation as a CI of steels is due to the formation of a polymolecular protective surface layer consisting of IFKhAN-92 molecules, Fe(II) cations and thiocyanate anions, which inhibits the reduction of $\mathrm{Fe}(\mathrm{III})$, and due to an additional decrease in the oxidative ability of Fe(III) cations by urotropine. The bibliography includes 122 references.
\end{abstract}

Received: July 2, 2021. Published: August 17, 2021

doi: $\underline{10.17675 / 2305-6894-2021-10-3-15}$

\footnotetext{
${ }^{1}$ The study was carried out within the Program for Basic Scientific Research of the Russian Federation Academies of Sciences for 2013-2020, subject "Development of the fundamental scientific basis of the protective effect of inhibitors of metal corrosion in gas and condensed media, nanocomposites, paintwork and conversion coatings" (state registration number AAAA-A18-118121090043-0).
} 
Keywords: corrosion mechanism, acid corrosion, steel, acid, steel etching, iron(III) chloride, iron(III) sulfate, iron(III) phosphate, $\mathrm{Fe}(I I I) / F e(I I)$ redox couple, diffusion of iron(III) cations, corrosion inhibitors.

\section{Introduction}

Important areas where mineral acid solutions are used on industrial scale include the metallurgical industry, the oil and gas complex, and housing and utility services [1-8]. The long-term operation of these media that are highly corrosive towards steel structures and manufactured products these media contact $[9,10]$ is accompanied by the accumulation of $\mathrm{Fe}(\mathrm{III})$ salts in these media, which can significantly affect the nature of steel corrosion in contact with acid solutions.

At metallurgical plants, semi-finished steel products are heated to such temperatures $(t)$ that intense oxidation of metal surfaces with atmospheric oxygen becomes possible. As a result, a layer of iron oxide phase called scale [11-19] is formed on the steel surface. The scale formed on low-carbon steels has an inhomogeneous structure and consists of the wustite $(\mathrm{FeO})$ phase immediately adjacent to the metal, which then turns to magnetite $\left(\mathrm{Fe}_{3} \mathrm{O}_{4}\right)$. The outside part of scale consists of the hematite phase $\left(\mathrm{Fe}_{2} \mathrm{O}_{3}\right)$. One of the ways to free the metal surface from scale is by acid etching [20-25]. The following processes occur in solutions of hydrochloric and sulfuric acids where scale is removed from steels:

$$
\begin{gathered}
\mathrm{Fe}+2 \mathrm{HCl}=\mathrm{FeCl}_{2}+\mathrm{H}_{2} \\
\mathrm{FeO}+2 \mathrm{HCl}=\mathrm{FeCl}_{2}+\mathrm{H}_{2} \mathrm{O} \\
\mathrm{Fe}_{3} \mathrm{O}_{4}+8 \mathrm{HCl}=\mathrm{FeCl}{ }_{2}+2 \mathrm{FeCl}_{3}+4 \mathrm{H}_{2} \mathrm{O} \\
\mathrm{Fe}_{2} \mathrm{O}_{3}+6 \mathrm{HCl}=2 \mathrm{FeCl}_{3}+3 \mathrm{H}_{2} \mathrm{O} \\
\mathrm{Fe}+\mathrm{H}_{2} \mathrm{SO}_{4}=\mathrm{FeSO}_{4}+\mathrm{H}_{2} \\
\mathrm{FeO}+\mathrm{H}_{2} \mathrm{SO}_{4}=\mathrm{FeSO}_{4}+\mathrm{H}_{2} \mathrm{O} \\
\mathrm{Fe}_{3} \mathrm{O}_{4}+4 \mathrm{H}_{2} \mathrm{SO}_{4}=\mathrm{FeSO}_{4}+\mathrm{Fe}_{2}\left(\mathrm{SO}_{4}\right)_{3}+4 \mathrm{H}_{2} \mathrm{O} \\
\mathrm{Fe}_{2} \mathrm{O}_{3}+3 \mathrm{H}_{2} \mathrm{SO}_{4}=\mathrm{Fe}_{2}\left(\mathrm{SO}_{4}\right)_{3}+3 \mathrm{H}_{2} \mathrm{O} .
\end{gathered}
$$

Reactions (1) and (5) occur at steel surface areas already freed from scale. Chemical reactions (3), (4), (7), and (8) should result in the accumulation of Fe(III) salts in acid solutions. Scale removal from the surface of low carbon steels has a complex mechanism. The specifics of the kinetics of scale acid etching and dissolution of its individual phases are considered in a number of studies [24-33]. An additional increase in the content of Fe(III) salts in etching solutions can be facilitated by the oxidation of $\mathrm{Fe}(\mathrm{II})$ salts formed upon dissolution of steel and the scale covering it in the acid in the presence of atmospheric oxygen. This is most often possible if the etching solution is operated incorrectly or in the case of a long downtime of the etching bath. 
According to [34-37], it often happens that all the Fe(III) entering the etching solution is completely consumed for the reaction with metallic iron, thus increasing its corrosion. This result allows one to write reactions (3), (4), (7) and (8) in a more general form:

$$
\begin{gathered}
\mathrm{Fe}_{3} \mathrm{O}_{4}+\mathrm{Fe}+8 \mathrm{HCl}=4 \mathrm{FeCl}_{2}+4 \mathrm{H}_{2} \mathrm{O}, \\
\mathrm{Fe}_{2} \mathrm{O}_{3}+\mathrm{Fe}+6 \mathrm{HCl}=3 \mathrm{FeCl}_{2}+3 \mathrm{H}_{2} \mathrm{O}, \\
\mathrm{Fe}_{3} \mathrm{O}_{4}+\mathrm{Fe}+4 \mathrm{H}_{2} \mathrm{SO}_{4}=4 \mathrm{FeSO}_{4}+4 \mathrm{H}_{2} \mathrm{O}, \\
\mathrm{Fe}_{2} \mathrm{O}_{3}+\mathrm{Fe}+3 \mathrm{H}_{2} \mathrm{SO}_{4}=3 \mathrm{FeSO}_{4}+3 \mathrm{H}_{2} \mathrm{O} .
\end{gathered}
$$

Nevertheless, accumulation of Fe(III) salts in etching solutions is possible.

The operation of acid formulations at oil and gas enterprises is also accompanied by the accumulation of $\mathrm{Fe}$ (III) salts therein [38]. The content of dissolved $\mathrm{Fe}$ (III) in $15 \% \mathrm{HCl}$ can reach $10 \mathrm{~g} / \mathrm{L}$ or more. The adverse effect of Fe(III) compounds in such media is primarily associated with their tendency to form insoluble compounds. The most efficient methods for preventing the adverse effects of the deposition of Fe(III) compounds from acid solutions imply the complexation of these ions with special chelating agents and reduction to less hazardous Fe(II) ions.

Cleaning and washing the internal surfaces of steel structures and equipment (steam boilers, process tanks, pipelines, etc.) from mineral deposits with acids necessarily involves the dissolution of corrosion products containing Fe(III). Under conditions of real production processes, the operation of acid solutions in contact with steel surfaces should be accompanied by accumulation of Fe(III) salts in them, which will change their properties significantly. The industrially used acid corrosion inhibitors (CI) of steels significantly lose their protective effect when Fe(III) salts are accumulated in a corrosive medium [39]. To estimate the corrosivity of acid solutions containing Fe(III) salts with respect to steels and to determine the prospects for the inhibitory of steels protection in these media, it is important to summarize and systematize the scattered literature data on this problem. In view of this, let us consider the specific features of the mechanisms of steel corrosion in acid media containing Fe(III) cations and the reasons for the loss of CI efficiency in these solutions.

The chemical composition of steels discussed in this review is given in Tables 1 and 2.

Table 1. Chemical composition of steels.

Steel brand

Steel 3

Steel 10

Steel 20

\section{Content elements in mass percent, $\%$}

0.14-0.22 C; $0.15-0.33 \mathrm{Si} ; 0.40-0.65 \mathrm{Mn}$; up to $0.3 \mathrm{Cr}$; up to $0.30 \mathrm{Ni}$; up to $0.008 \mathrm{~N}$; up to $0.30 \mathrm{Cu}$; up to $0.05 \mathrm{~S}$; up to $0.04 \mathrm{P}$; up to $0.08 \mathrm{As}$; remainder $\mathrm{Fe}$

0.07-0.14 C; $0.17-0.37 \mathrm{Si} ; 0.35-0.65 \mathrm{Mn}$; up to $0.15 \mathrm{Cr}$; up to $0.25 \mathrm{Ni}$; up to $0.25 \mathrm{Cu}$; up to $0.04 \mathrm{~S}$; up to $0.035 \mathrm{P}$; up to $0.08 \mathrm{As}$; remainder Fe 
Steel brand

\begin{tabular}{|c|c|}
\hline Steel 45 & $\begin{array}{l}0.42-0.5 \mathrm{C} ; 0.17-0.37 \mathrm{Si} ; 0.5-0.8 \mathrm{Mn} \text {; up to } 0.25 \mathrm{Cr} \text {; up to } 0.25 \mathrm{Ni} \text {; up to } 0.25 \\
\mathrm{Cu} \text {; up to } 0.04 \mathrm{~S} \text {; up to } 0.035 \mathrm{P} \text {; up to } 0.08 \mathrm{As} \text {; remainder } \mathrm{Fe}\end{array}$ \\
\hline 2Kh13 & $\begin{array}{l}0.16-0.25 \mathrm{C} \text {; up to } 0.6 \mathrm{Si} \text {; up to } 0.6 \mathrm{Mn} ; 12-14 \mathrm{Cr} \text {; up to } 0.6 \mathrm{Ni} \text {; up to } 0.025 \mathrm{~S} \text {; } \\
\text { up to } 0.03 \mathrm{P} \text {; remainder } \mathrm{Fe}\end{array}$ \\
\hline Kh18N10T & $\begin{array}{l}\text { up to } 0.12 \mathrm{C} \text {; up to } 0.8 \mathrm{Si} \text {; up to } 2 \mathrm{Mn} \text {; } 9-11 \mathrm{Ni} \text {; up to } 0.02 \mathrm{~S} \text {; up to } 0.035 \mathrm{P} \text {; } \\
\qquad 17-19 \mathrm{Cr} \text {; up to } 0.3 \mathrm{Cu} \text {; up to } 0.5 \mathrm{Ti} \text {; remainder } \mathrm{Fe}\end{array}$ \\
\hline Steel KhVG & $\begin{array}{c}0.9-1.05 \mathrm{C} ; 0.1-0.4 \mathrm{Si} ; 0.8-1.1 \mathrm{Mn} \text {; up to } 0.35 \mathrm{Ni} \text {; up to } 0.03 \mathrm{~S} \text {; up to } 0.03 \mathrm{P} \text {; } \\
0.9-1.2 \mathrm{Cr} \text {; up to } 0.3 \mathrm{Mo} ; 1.2-1.6 \mathrm{~W} \text {; up to } 0.3 \mathrm{Cu} \text {; remainder } \mathrm{Fe}\end{array}$ \\
\hline 08PS & $\begin{array}{l}0.05-0.11 \mathrm{C} ; 0.05-0.17 \mathrm{Si} ; 0.35-0.65 \mathrm{Mn} \text {; up to } 0.1 \mathrm{Cr} \text {; up to } 0.25 \mathrm{Ni} \text {; up to } \\
0.25 \mathrm{Cu} \text {; up to } 0.04 \mathrm{~S} \text {; up to } 0.035 \mathrm{P} \text {; up to } 0.08 \mathrm{As} \text {; remainder } \mathrm{Fe}\end{array}$ \\
\hline 410 Stainless Steel & $\begin{array}{c}\text { 0.09 C; } 0.27 \mathrm{Si} ; 0.44 \mathrm{Mn} ; 0.24 \mathrm{Ni} ; 0.022 \mathrm{~S} ; 0.024 \mathrm{P} ; 12.39 \mathrm{Cr} ; 0.07 \mathrm{Mo} ; 0.12 \\
\mathrm{Cu} \text {; remainder Fe }\end{array}$ \\
\hline $\begin{array}{l}2205 \text { Duplex } \\
\text { Stainless Steel }\end{array}$ & $\begin{array}{c}0.024 \mathrm{C} ; 0.62 \mathrm{Si} ; 1.42 \mathrm{Mn} ; 5.46 \mathrm{Ni} ; 0.001 \mathrm{~S} ; 0.024 \mathrm{P} ; 21.13 \mathrm{Cr} ; 3.11 \mathrm{Mo} ; 0.15 \\
\text { N; remainder Fe }\end{array}$ \\
\hline 304 Stainless Steel & $\begin{array}{l}\text { up to } 0.08 \mathrm{C} \text {; up to } 2 \mathrm{Mn} ; 8.0-10.5 \mathrm{Ni} \text {; up to } 0.03 \mathrm{~S} \text {; up to } 0.045 \mathrm{P} ; 18-20 \mathrm{Cr} \text {; } \\
\text { up to } 1.0 \mathrm{Cu} \text {; remainder } \mathrm{Fe}\end{array}$ \\
\hline EI 531 & $\begin{array}{c}0.07-0.12 \mathrm{C} ; 0.35-0.5 \mathrm{Si} ; 0.5-0.7 \mathrm{Mn} ; 1.9-2.4 \mathrm{Cr} ; 0.1-0.3 \mathrm{~V} ; 0.4-0.6 \mathrm{Mo} ; \\
0.4-0.6 \mathrm{Nb} \text {; up to } 0.025 \mathrm{~S} \text {; up to } 0.035 \mathrm{P} \text {; remainder } \mathrm{Fe}\end{array}$ \\
\hline ARMCO Pure Iron & up to $0.02 \mathrm{C} ; 99.8-99.9 \mathrm{Fe}$ \\
\hline
\end{tabular}

Table 2. Chemical composition of corrosion inhibitors.

\section{Content elements in mass percent, $\%$}


Label

Chemical composition

\begin{tabular}{cc}
\hline I-1-A & A mixture of modified polyalkylpyridines \\
\hline I-1-V & A mixture of modified polyalkylpyridines \\
\hline PKU-E & $\left.\left[\left(\mathrm{CH}_{2}=\mathrm{N}-\mathrm{CH}_{2}\right)_{3} \mathrm{~N}-\mathrm{CH}_{2} \mathrm{C}_{6} \mathrm{H}_{5}\right)\right] \mathrm{Cl}$ \\
\hline Catamine AB & $\begin{array}{c}\text { A mixture of alkylbenzyldimethylammonium chlorides } \\
\left(\left[\mathrm{C}_{n} \mathrm{H}_{2 n+1} \mathrm{~N}^{+}\left(\mathrm{CH}_{3}\right)_{2} \mathrm{CH}_{2} \mathrm{C}_{6} \mathrm{H}_{5}\right] \mathrm{Cl}^{-}, \text {where } n=10-18\right)\end{array}$ \\
\hline IFKhAN-92 & A derivative of substituted 1,2,4-triazole \\
\hline
\end{tabular}

\section{The physicochemical properties of acids containing iron(III) salts}

The corrosivity of environments to metals is largely determined by their physicochemical properties. The knowledge of these properties is important for understanding the mechanism of metal corrosion and in the directed search for methods of anticorrosive protection of a metal in such an environment. In acid solutions, protons are the corrosive component of the corrosive medium. In acids containing $\mathrm{Fe}$ (III) salts, an additional corrosive component appears, viz., the Fe(III) cations. An important thermodynamic parameter of such systems is the redox potential $(E)$ that characterizes their oxidizing ability. In the systems we studied, the potential is determined by the equilibrium reaction:

$$
\mathrm{Fe}^{3+}+\mathrm{e}^{-}=\mathrm{Fe}^{2+} .
$$

Potentiometry is the simplest way to measure it [40-44]. A number of studies $[27,45,46]$ have shown that the $E$ value of the $\mathrm{Fe}(\mathrm{III}) / \mathrm{Fe}(\mathrm{II})$ redox couple in solutions of mineral acids is lower than the theoretical value. The value of $E_{\mathrm{Fe}(\mathrm{III}) / \mathrm{Fe} \text { (II) }}$ decreases in the series: $\mathrm{HClO}_{4}>\mathrm{HBr}>\mathrm{H}_{2} \mathrm{SO}_{4}>\mathrm{HCl}>\mathrm{H}_{3} \mathrm{PO}_{4}>\mathrm{HF}$ (Figure 1) [46]. The observed effect is determined by the ability of mineral acid anions to bind Fe(III) cations into complex compounds whose oxidizing ability is lower than that of hydrate complexes. This is confirmed by the data on the complexing ability of Fe(III) cations with mineral acid anions presented in Table 3. According to potentiometric data, phosphate and, especially, fluoride anions form the strongest complexes with Fe(III) cations. Spectrophotometric data confirm that Fe(III) ions are bound into phosphate complexes in acid media [47-49].

Valuable information about the properties of solutions containing $\mathrm{Fe}$ (III) cations is provided by studies using the cyclic voltammetry method $(\mathrm{CV})$ on various inert electrodes [50-59]. It was shown by $\mathrm{CV}$ on a platinum electrode [60-62] that binding of $\mathrm{Fe}$ (III) cations into phosphate and, especially, fluoride complex compounds in acid solutions decreased not only their oxidizing ability but also their mobility. In $2 \mathrm{M} \mathrm{HCl}+\mathrm{H}_{3} \mathrm{PO}_{4}$ and $\mathrm{H}_{2} \mathrm{SO}_{4}+\mathrm{H}_{3} \mathrm{PO}_{4}$ containing $0.10 \mathrm{M} \mathrm{Fe}(\mathrm{III})$, a systematic increase in the content of $\mathrm{H}_{3} \mathrm{PO}_{4}$ (Figure 2) results in a decrease in the diffusion coefficient of $\mathrm{Fe}$ (III) cations $\left(D_{\mathrm{Fe}(\mathrm{III})}\right)$ [61, 62]. In a number of studies, the $D_{\mathrm{Fe}(\mathrm{III})}$ values in aqueous solutions were determined from electrochemical data obtained on inert metal rotating electrodes of various shapes [63, 64]. However, as noted in [63], this approach shows a significant scatter of results obtained under similar conditions, 
which can be explained by the design of the working electrode, its preparation and surface condition, differences in research methods, and adsorption of impurities. In addition to electrochemical methods, the gel diaphragm method can be used to determine the $D_{\mathrm{Fe}(\mathrm{III})}$ values in acid media [65].

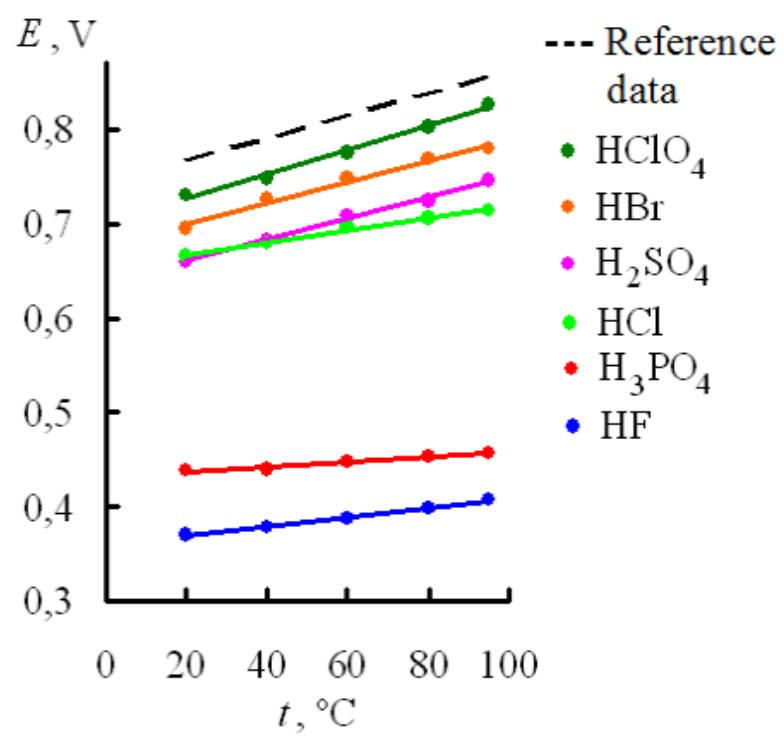

Figure 1. Potentials of a platinum electrode in argon-deaerated $2 \mathrm{M}$ mineral acids containing $0.05 \mathrm{M} \mathrm{Fe}(\mathrm{III})$ and $0.05 \mathrm{M} \mathrm{Fe}(\mathrm{II})$ at various temperatures.

Table 3. Instability constants $\left(p K_{\mathrm{i}}\right)$ of $\mathrm{Fe}(\mathrm{III})$ complexes with some inorganic ligands. $t=20-30^{\circ} \mathrm{C}[46]$.

\begin{tabular}{ccccccc}
\hline Ligands & $p \mathbf{K}_{\mathbf{i 1}}$ & $p \mathbf{K}_{\mathbf{i 1}, \mathbf{2}}$ & $\boldsymbol{p} \mathbf{K}_{\mathbf{i 1}-3}$ & $p \mathbf{K}_{\mathbf{i 1}-\mathbf{4}}$ & $p \mathbf{K}_{\mathbf{i 1}-5}$ & $p \mathbf{K}_{\mathbf{i 1}-\mathbf{6}}$ \\
\hline $\mathrm{ClO}_{4}^{-}$ & 1.15 & - & - & - & - & - \\
& 1.0 & - & - & - & - & - \\
$\mathrm{SO}_{4}^{2-}$ & 4.18 & 7.4 & - & - & - & - \\
& 4.02 & 5.38 & - & - & - & - \\
$\mathrm{HSO}_{4}^{-}$ & 2.48 & - & - & - & - & - \\
$\mathrm{HPO}_{4}^{2-}$ & 3.5 & - & - & 9.15 & - & - \\
$\mathrm{H}_{2} \mathrm{PO}_{4}^{-}$ & 9.75 & - & - & - & - & - \\
$\mathrm{F}^{-}$ & 6.04 & 10.74 & 13.74 & 15.74 & 16.10 & $\approx 16.10$ \\
& 1.45 & 2.10 & 1.10 & -0.85 & - & - \\
$\mathrm{Cl}^{-}$ & 1.52 & 2.22 & - & - & - & - \\
& 1.48 & 2.13 & 1.13 & - & - & - \\
$\mathrm{Br}^{-}$ & 0.55 & 0.82 & - & - & - & - \\
\hline
\end{tabular}




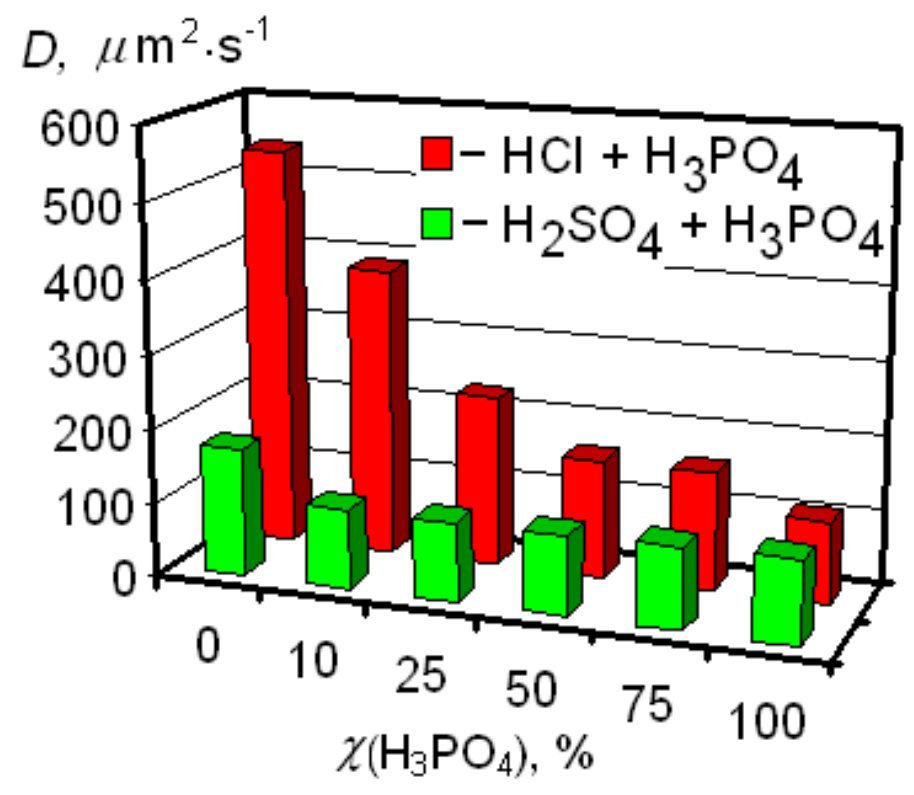

Figure 2. Effect of $\mathrm{H}_{3} \mathrm{PO}_{4}$ concentration in a $\mathrm{HCl}+\mathrm{H}_{3} \mathrm{PO}_{4}+0.10 \mathrm{M} \mathrm{Fe}(\mathrm{III})$ and $\mathrm{H}_{2} \mathrm{SO}_{4}+$ $\mathrm{H}_{3} \mathrm{PO}_{4}+0.10 \mathrm{M} \mathrm{Fe}(\mathrm{III})$ systems on the diffusion coefficient of the $\mathrm{Fe}(\mathrm{III})$ cation. $t=25^{\circ} \mathrm{C}$.

Thus, the physicochemical parameters of acid solutions containing Fe(III) salts are largely determined by their anionic composition. The stronger the acid anions bind $\mathrm{Fe}(\mathrm{III})$ cations into complex compounds, the stronger the decrease in the oxidizing properties of the solution and the mobility of the corrosive component, $\mathrm{Fe}$ (III), in it. Binding of Fe(III) cations into complex compounds by the components of an acid solution changes the thermodynamic and kinetic characteristics of such systems. The observed effect makes it possible to predict and control the properties of acid solutions containing $\mathrm{Fe}$ (III) salts. Addition of acids $\left(\mathrm{H}_{3} \mathrm{PO}_{4}\right.$ or $\mathrm{HF}$ ) that dissociate to generate anions capable of forming complexes with $\mathrm{Fe}(\mathrm{III})$ can decrease the corrosivity of such media significantly. $\mathrm{H}_{3} \mathrm{PO}_{4}$ is more promising in this respect. In contrast, HF solutions are not readily acceptable for practical application because of its high corrosivity towards a wide range of materials and high toxicity. Apparently, the accumulation of $\mathrm{Fe}$ (III) in widely used solutions of $\mathrm{HCl}$ and $\mathrm{H}_{2} \mathrm{SO}_{4}$ is most dangerous since it greatly increases the corrosivity of these media.

\section{Specific features of steel corrosion in acid solutions containing $\mathrm{Fe}$ (III) salts}

In simplified form, the process of steel corrosion in acid solutions containing Fe(III) salts is described by two parallel reactions:

$$
\begin{gathered}
\mathrm{Fe}+2 \mathrm{H}^{+}=\mathrm{Fe}^{2+}+\mathrm{H}_{2}, \\
\mathrm{Fe}+2 \mathrm{Fe}^{3+}=3 \mathrm{Fe}^{2+}
\end{gathered}
$$

Reaction (14) describes the reaction of the metal with an acid, while reaction (15), the reaction with a Fe(III) salt. Let us consider the features of these processes in more detail. 
The studies of the corrosion of steels in solutions containing Fe(III) salts encounter some experimental difficulties. As we'll show below, the reduction of Fe(III) cations occurs in the diffusion mode. In general, this makes the corrosion process sensitive to the hydrodynamic parameters of the corrosive medium. The most adequate study of steel corrosion, both based on the mass loss of samples and by electrochemical methods, is possible only if the hydrodynamic parameters of the solution are controlled. A standard solution to this problem makes use of a rotating disc electrode. The theoretical and applied aspects of how electrochemical reactions occur on rotating electrodes of various shapes are analyzed in reviews [66-69]. Let us consider the design of an experimental device (Figure 3) for studying the corrosion of steels in acidic media containing Fe(III) salts created at the Department of General and Analytical Chemistry of the Moscow State Pedagogical Institute [70]. A fundamentally important feature of this corrosion setup is that the disk electrode has the working surface on top, which considerably minimizes the screening effect of gaseous hydrogen released on the metal. A steel sample is rotated by an axis arranged below it, which eliminates the distortion of the convective solution flow to the working disk surface. This device makes it possible, by using a burette filled with water, to measure the volume of hydrogen gas evolved on the steel sample. The device is also equipped with a vessel for preliminary thermal stabilization and deaeration of the test solution while its contact with the test electrode is prevented. This setup makes it possible to study steel corrosion in acid solutions both in terms of mass loss of samples and by a set of electrochemical methods. Moreover, the setup contains inputs for sensors that allow one to monitor the solution conductivity and acidity.

A study of this process in a stream of concentrated $\mathrm{FeCl}_{3}$ solutions provided important information on the regularities of corrosion of various steels in acid media containing $\mathrm{Fe}$ (III) salts [71]. In $0.5-4.3 \mathrm{M} \mathrm{FeCl}_{3}$ and $1 \mathrm{HCl}+0.5-4.3 \mathrm{M} \mathrm{FeCl}_{3}$, the corrosion of low-carbon (steel 3), low-alloy (2Kh13) and chromium-nickel (Kh18N10T) steels occurs at high rates ( $k$ ) (Figure 4a). In all the cases, the plot of $k v s$. $C_{\mathrm{Fe}(\mathrm{III})}$ passes through an extremum in the concentration range studied, and the maximum corrosion rate is observed at $C_{\mathrm{Fe} \text { (III) }}=2.25-$ $2.75 \mathrm{M}$. In $\mathrm{FeCl}_{3}$ solutions, the corrosion of steel 3 and steel $2 \mathrm{Kh} 13$ is uniform, while Kh18N10T steel undergoes pitting corrosion, which indicates the instability of its passive state. The corrosion rates of steel 3 and steel $2 \mathrm{Kh} 13$ in $1 \mathrm{M} \mathrm{HCl}+\mathrm{FeCl}_{3}$ are the same as in the $\mathrm{FeCl}_{3}$ solution, but that of steel Kh18N10T is higher in $1 \mathrm{HCl}+\mathrm{FeCl}_{3}$ at $C_{\mathrm{Fe}(\mathrm{III})}<2 \mathrm{M}$. Pitting corrosion of Kh18N10T steel does not occur in this environment. Within the experimental scatter, steel 45 and steel KhVG behave similarly to steel 3. An increase in the temperature of the $\mathrm{FeCl}_{3}$ solution accelerates the corrosion of steel 3 (Figure $4 \mathrm{~b}$ ). At $C_{\mathrm{Fe}(\mathrm{III})}$ $=0.90,2.25$, and $3.15 \mathrm{M}$, the activation energy $\left(E_{\text {act }}\right)$ of steel 3 corrosion in this environment is $5.4,9.8$, and $14.2 \mathrm{~kJ} / \mathrm{mol}$, respectively, which is typical of processes that occur under diffusion control. 


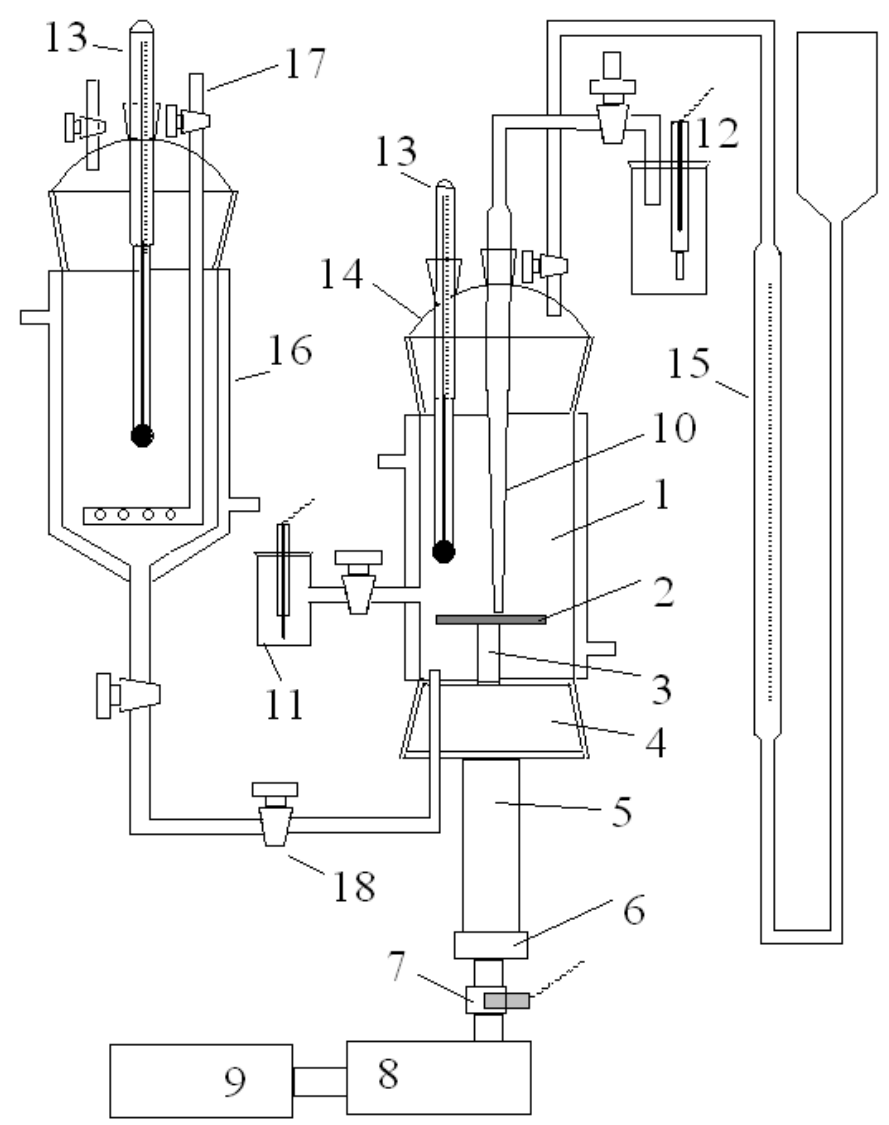

Figure 3. Device with a rotating disk sample for corrosion testing. 1 - thermostatically controlled glass cell for corrosion and electrochemical measurements, 2 - rotating disk electrode with isolated bottom and side parts of the surface, 3 - metal axis in a glass isolated tube, 4 fluoroplastic plug, 5 - tube with located in it: metal axis, fluoroplastic glands, bushing, cone, bearings and rubber insulation, 6 - union nut, 7 - contact brush, 8 - reducer, 9 - electric motor, 10 - electrolytic key, 11 - vessel with an platinum auxiliary electrode, 12 - silver chloride electrode, 13 - thermometer, 14 - glass cover, 15 - burette for measuring the volume of evolved hydrogen gas, 16 - temperature-controlled vessel for preliminary preparation of the test solution, 17 - device for passing gas bubbles through a liquid layer, 18 - three way glass faucet.

Valuable information for understanding the corrosion mechanism of low-carbon steel in $\mathrm{FeCl}_{3}$ solutions is obtained by analyzing the plot of $k v s$. the flow velocity of the corrosive medium (Figure 5). It is linear in $1.30 \mathrm{M} \mathrm{FeCl}_{3}$, but more complex in $3.15 \mathrm{M} \mathrm{FeCl}_{3}$. The deviation of the plot from linearity results from the formation of sludge, which can easily be removed with filter paper, on the steel disk surface. At low disk rotation rates, it almost does not slow down the supply of Fe(III) cations to the steel surface. At high rotation rates, the sludge is accumulated more strongly, which creates diffusion limitations to the penetration of $\mathrm{Fe}$ (III) cations to the surface and slows down overall corrosion. The role of the inhibitory effect of sludge on the corrosion of steels in concentrated $\mathrm{FeCl}_{3}$ solutions was confirmed by experiments with its periodic mechanical removal from the surface of steel samples during the experiment (Table 4). Sludge formed on a steel disk in $1.35 \mathrm{M} \mathrm{FeCl}_{3}$ almost does not slow down the dissolution of steel, but it is significant in $3.15 \mathrm{M} \mathrm{FeCl}_{3}$. 

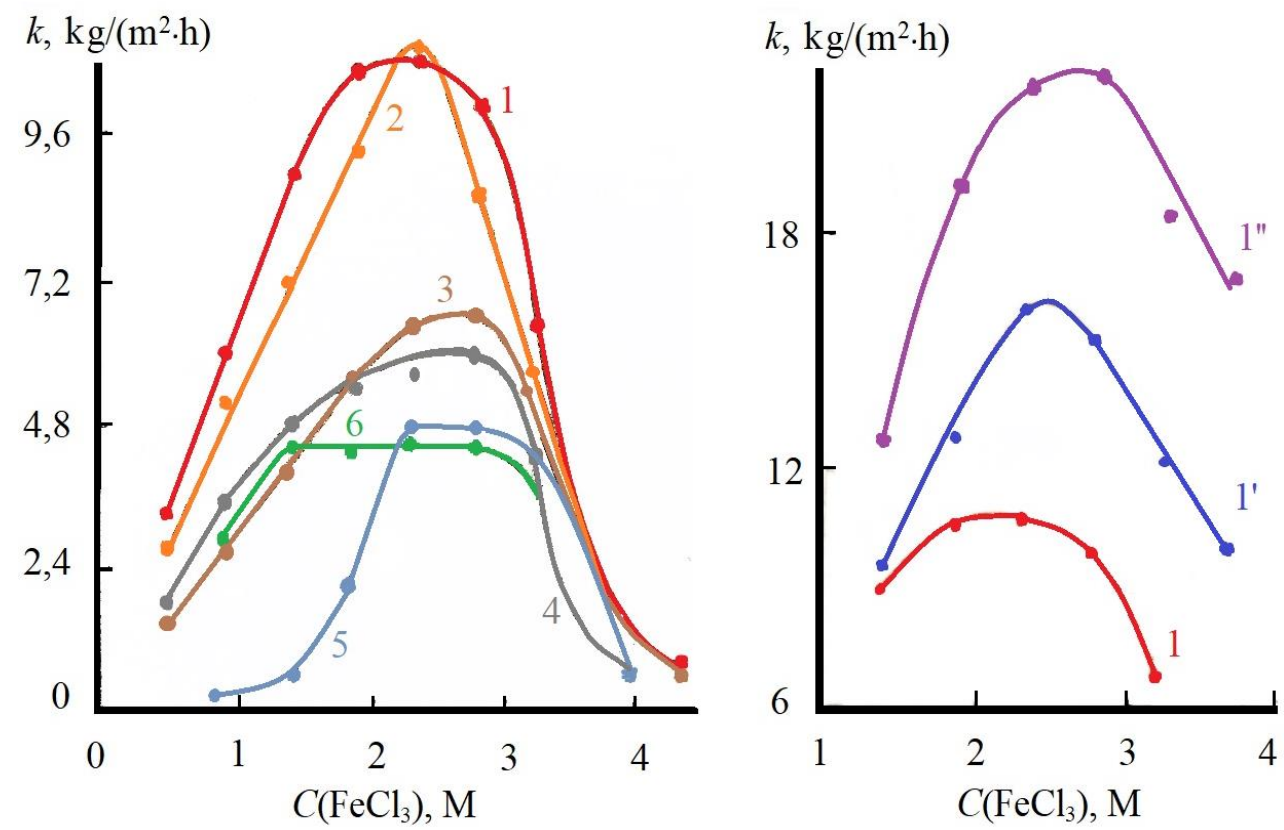

Figure 4. Variation of the corrosion rate of steels $v s$. $\mathrm{Fe}(\mathrm{III})$ concentration in a $\mathrm{FeCl}_{3}$ solutions $\left(1,1^{\prime}, 1^{\prime \prime}, 3,5\right)$ and $1 \mathrm{M} \mathrm{HCl}+\mathrm{FeCl}_{3}(2,4,6)$. Rotation rate of disk samples $-2300 \mathrm{rpm} .1,1^{\prime}$, $1^{\prime \prime}, 2$ - steel $3 ; 3,4-2 \mathrm{Kh} 13$ steel; $5,6-\mathrm{Kh} 18 \mathrm{~N} 10 \mathrm{~T}$ steel. $1-6-20^{\circ} \mathrm{C}, 1^{\prime}-50^{\circ} \mathrm{C}, 1^{\prime \prime}-80^{\circ} \mathrm{C}$.

In general, the very high corrosivity of concentrated $\mathrm{FeCl}_{3}$ solutions toward steels, where the weight loss of the samples amounts to kilograms per $\left(\mathrm{m}^{2} \cdot \mathrm{h}\right)$, should be noted. Similar high corrosion rates of steels are observed only in high-temperature solutions of mineral acids [72].

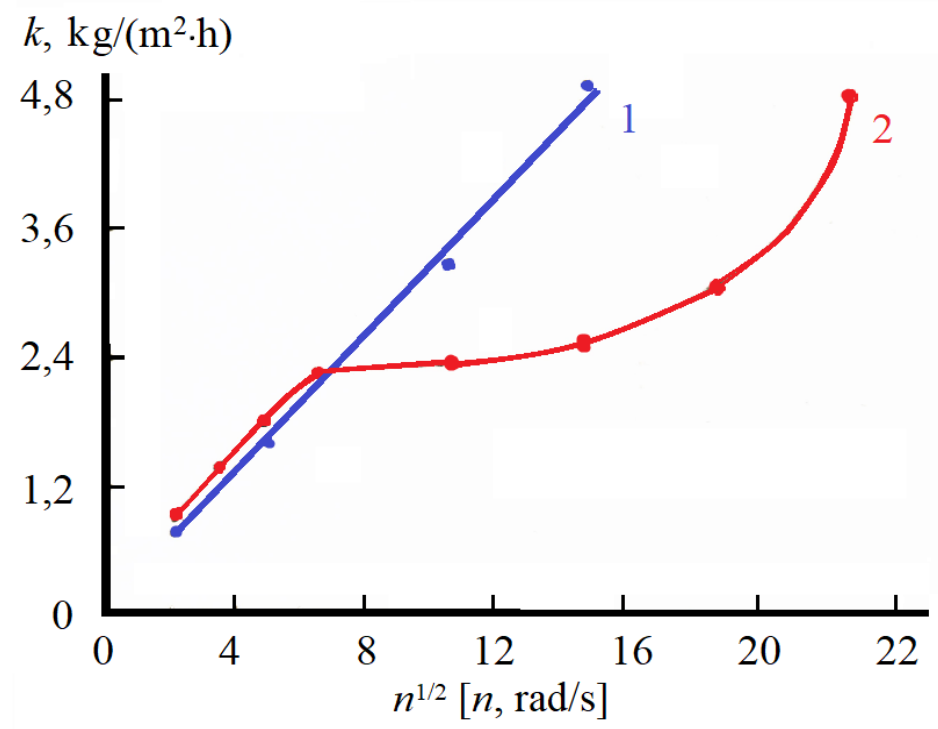

Figure 5. Variation of the corrosion rate of steel $3 v s$. the square root of rotational speed of the disk sample in $\mathrm{FeCl}_{3}$ solutions with a concentration, $\mathrm{M}: 1-1.30,2-3.15 . t=20^{\circ} \mathrm{C}$. 
Table 4. Influence of periodic mechanical removal of sludge from the surface of rotating disk samples of steel $3(n=2300 \mathrm{rpm})$ on their corrosion rate $(k)$ in $\mathrm{FeCl}_{3}$ solutions. Test duration -6 min. $t=24^{\circ} \mathrm{C}$.

\begin{tabular}{|c|c|c|c|c|}
\hline \multirow[b]{2}{*}{$C_{\mathrm{Fe}(\mathrm{III}), \mathrm{M}}$} & \multicolumn{3}{|c|}{$k, \mathrm{~kg} /\left(\mathrm{m}^{2} \cdot \mathrm{h}\right)$} & \multirow{2}{*}{$\begin{array}{c}\text { Corrosion } \\
\text { acceleration } \\
\text { coefficients at } \\
\text { four removal of } \\
\text { sludge }\end{array}$} \\
\hline & $\begin{array}{c}\text { Without removal } \\
\text { of sludge }\end{array}$ & $\begin{array}{c}\text { Two removal of } \\
\text { sludge, each after } \\
2 \text { min }\end{array}$ & $\begin{array}{c}\text { Four removal of } \\
\text { sludge, each after } \\
1 \text { min }\end{array}$ & \\
\hline 1.35 & 5.31 & 5.63 & 5.43 & 1.02 \\
\hline 2.25 & 5.26 & 6.99 & 7.31 & 1.39 \\
\hline 3.15 & 2.61 & 3.75 & 4.47 & 1.71 \\
\hline
\end{tabular}

Voltammetric studies on the behavior of steel and platinum rotating disk electrodes in highly concentrated $\mathrm{FeCl}_{3}$ solutions $(1.30-4.12 \mathrm{M}$ ) show that the diffusion of $\mathrm{Fe}(\mathrm{III})$ cations to a metal surface is the limiting stage of dissolution of steel 3 in these media [73]. In these media, the corrosion rate of steel is determined by the content of Fe(III), the solution viscosity $(\eta)$, the diffusion coefficient of $\mathrm{Fe}(\mathrm{III})$ cations $\left(D_{\mathrm{Fe}(\mathrm{III})}\right)$, and the intensity of the formation of a sludge layer that prevents the penetration of a corrosive solution to the metal surface. The effects of these factors on the corrosion of steel in $\mathrm{FeCl}_{3}$ solutions were separated (Figure 6). Curve 1 was obtained from the weight loss of steel samples under real corrosion process conditions where, with an increase in the $\mathrm{FeCl}_{3}$ content in the solution, its $\eta$ increases, $D_{\text {Fe (III) }}$ decreases, and formation of surface sludge increases. The shape of curve 1 reflects the effect of all these factors. Curve 2 was obtained from the data on the limiting diffusion current $\left(i_{\mathrm{d}}\right)$ of $\mathrm{Fe}(\mathrm{III})$ reduction on a platinum electrode in similar media. Since no sludge formation on an inert platinum electrode occurs, the shape of the curve results only from the variation in $\eta$ and $D_{\mathrm{Fe}(\mathrm{III})}$. Curve 3 shows the result of the process simulation taking into account the Levich equation, according to which, if $\eta$ and $D_{\mathrm{Fe}(\mathrm{III})}$ are constant, the $i$ values are directly proportional to $C_{\mathrm{Fe}(\mathrm{III})}$.

It is noted that in dilute $\mathrm{HCl}$ solutions in the presence of significant amounts of $\mathrm{FeCl}_{3}$ [74], no evolution of gaseous hydrogen on the surface of corroding steel occurs in the initial period of time (Figure 7). The observed effect is associated with the reduction of Fe(III) cations on a steel surface, which increases the metal corrosion potential $\left(E_{\text {cor }}\right)$ and thus decreases the hydrogen evolution rate. Direct interaction of Fe(III) ions with adsorbed hydrogen atoms cannot be ruled out, either.

$$
\mathrm{Fe}^{3+}+\mathrm{H}_{\mathrm{ad}}=\mathrm{Fe}^{2+}+\mathrm{H}^{+}
$$

This reaction prevents the evolution of gaseous hydrogen from the metal surface. 


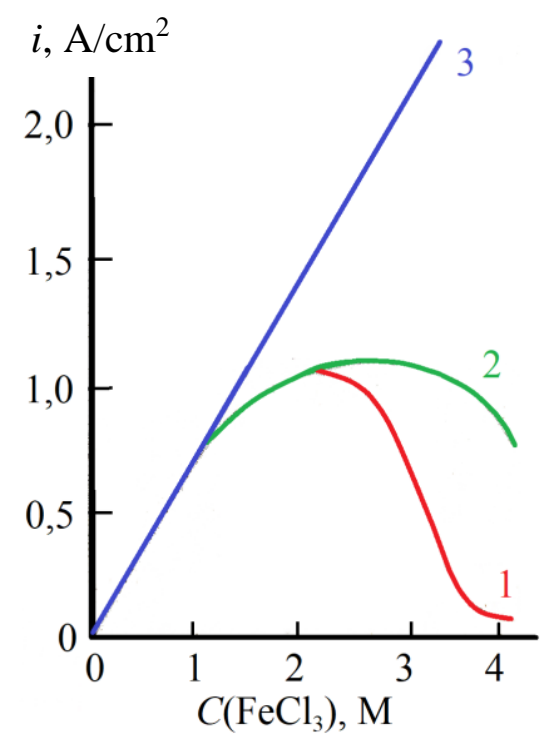

Figure 6. Corrosion rate of steel 3 (rotating disk electrode, $n=2300 \mathrm{rpm}$ ) in $\mathrm{FeCl}_{3}$ solutions. 1 - under real conditions of the corrosion process, 2 - in the absence of sludge on the surface of the samples, 3 - provided that the viscosity of the solution remains unchanged and there is no sludge on the surface of the samples. $t=20^{\circ} \mathrm{C}$.

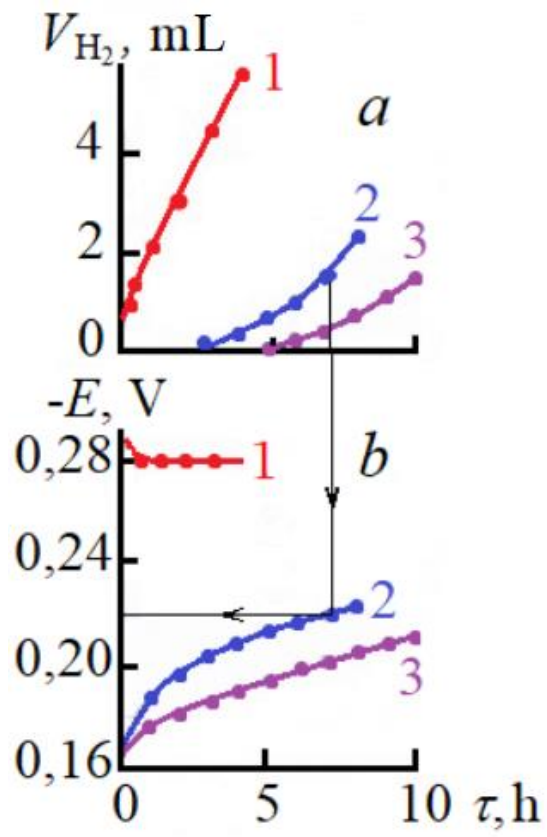

Figure 7. The volume of evolved hydrogen $(a)$ and the electrode potential of steel $3(b)$ in static $\mathrm{HCl}$ solutions ( $\mathrm{pH} 0.4$ ) containing $\mathrm{FeCl}_{3}$ with a concentration, $\mathrm{g} / \mathrm{L}: 1-0 ; 2,3-5$. The ratio of the $\mathrm{HCl}$ solution volume to the surface area of steel samples, $\mathrm{mL} / \mathrm{cm}^{2}: 2-10 ; 3-20$.

In more concentrated solutions of mineral acids containing $\mathrm{Fe}(\mathrm{III})$ salts, the corrosion of low-carbon steels occurs through two independent processes (14) and (15). The features of these processes were analyzed in [75] and are discussed below. Process (14) is the result of four partial reactions: 
anodic dissolution of iron

$$
\mathrm{Fe}-2 \mathrm{e}=\mathrm{Fe}^{2+},
$$

cathodic deposition of iron

$$
\mathrm{Fe}^{2+}+2 \mathrm{e}=\mathrm{Fe},
$$

cathodic evolution of hydrogen

$$
2 \mathrm{H}^{+}+2 \mathrm{e}=\mathrm{H}_{2}
$$

and its anodic ionization

$$
\mathrm{H}_{2}-2 \mathrm{e}=2 \mathrm{H}^{+} .
$$

Corrosion results from the predominant reactions (17) and (19).

The cathodic hydrogen evolution consists of several sequential stages, e.g., the transfer of $\mathrm{H}^{+}$from the acid bulk to a metal surface $\left(\left(\mathrm{H}^{+}\right) *\right.$ is the hydrogen ion closest to the metal surface),

$$
\mathrm{H}^{+} \rightarrow\left(\mathrm{H}^{+}\right) *,
$$

and the charge transfer (Volmer) reaction

$$
\left(\mathrm{H}^{+}\right) *+\mathrm{e} \rightarrow \mathrm{H}_{\mathrm{ad}},
$$

which is followed by a stage of chemical recombination (the Tafel reaction),

$$
\mathrm{H}_{\mathrm{ad}}+\mathrm{H}_{\mathrm{ad}} \rightarrow\left(\mathrm{H}_{2}\right)_{\mathrm{ad}}
$$

or a stage of electrochemical recombination (the Heyrovsky reaction),

$$
\mathrm{H}_{\mathrm{ad}}+\left(\mathrm{H}^{+}\right)_{*}+\mathrm{e} \rightarrow\left(\mathrm{H}_{2}\right)_{\mathrm{ad}} .
$$

The set of stages (22) and (23) is called the Volmer-Tafel mechanism, and the set of reactions (22) and (24) is called the Volmer-Heyrovsky mechanism. It is believed that both mechanisms take place on steel surfaces.

The mechanism of iron anodic dissolution is equally obscure. Heusler assumed that the reaction between the $\mathrm{Fe}$ crystal lattice atoms and adsorbed $\mathrm{OH}^{-}$ions leads to the formation of $\mathrm{FeOH}_{\mathrm{ad}}$ :

$$
\mathrm{Fe}+\mathrm{OH}_{\mathrm{ad}}^{-} \rightarrow \mathrm{FeOH}_{\mathrm{ad}}+\mathrm{e} .
$$
layer:

It is believed that this compound catalyzes the transfer of a Fe(II) ion through the double

$$
\mathrm{Fe}+\mathrm{OH}_{\mathrm{ad}}^{-}+\mathrm{FeOH}_{\mathrm{ad}} \rightarrow\left(\mathrm{FeOH}^{+}\right)_{*}+\mathrm{FeOH}_{\mathrm{ad}}+2 \mathrm{e} .
$$

In an acidic solution of the compounds, $\mathrm{FeOH}^{+}$decomposes slowly as follows:

$$
\left(\mathrm{FeOH}^{+}\right)_{*}+\left(\mathrm{H}^{+}\right)_{*} \rightarrow\left(\mathrm{Fe}^{2+}\right)_{*}+\mathrm{H}_{2} \mathrm{O} \text {. }
$$

In contrast, Bockris considered $\mathrm{FeOH}$ to be an intermediate product of the single-stage reaction: 


$$
\begin{gathered}
\mathrm{Fe}+\mathrm{OH}^{-} \rightarrow \mathrm{FeOH}+\mathrm{e}, \\
\mathrm{FeOH} \rightarrow \mathrm{FeOH}^{+}+\mathrm{e} \\
\mathrm{FeOH}^{+} \rightarrow \mathrm{Fe}^{2+}+\mathrm{OH}^{-}
\end{gathered}
$$

More complicated mechanisms of the anodic reaction of iron suggested by Kolotyrkin, Chin and Nobe allow it to involve not only $\mathrm{OH}^{-}$ions but also anions formed upon acid dissociation.

Process (15) is the result of anodic (17) and cathodic reactions:

$$
\mathrm{Fe}^{3+}+\mathrm{e}^{-}=\mathrm{Fe}^{2+} \text {. }
$$

Processes (14) and (15) involve the same anodic reaction (17). Based on this, the corrosion of low-carbon steel is determined by three independent partial reactions: cathodic reduction of $\mathrm{H}^{+}$(19) and $\mathrm{Fe}(\mathrm{III})$ (31), as well as anodic ionization of iron (17) [75]. Using voltammetric studies of a steel electrode, it was shown that corrosion under these conditions occurred in the region of active metal dissolution. Reactions (17) and (19) are characterized by kinetic control, whereas reaction (31), by diffusion control. A study on the cathodic reduction of $\mathrm{Fe}(\mathrm{III})$ on a steel surface using a rotating disk electrode shows that the cathodic reaction is accelerated by an increase in the content of $\mathrm{Fe}$ (III) in the solution and an increase in the frequency of electrode rotation that accelerate the transfer of the solution to the metal surface. The dependence of the reaction rate on the disk rotation rate is well described by the equation [66]:

$$
i_{\mathrm{d}}=0.62 z F C^{*} D^{2 / 3} \eta^{-1 / 6} n^{1 / 2},
$$

where $z$ is the number of electrons participating in the electrode reaction; $F$ is the Faraday number; $C^{*}$ is the $\mathrm{Fe}$ (III) bulk concentration in the solution; $D$ is the diffusion coefficient of the electroactive particle; $\eta$ is the kinematic liquid viscosity, and $n$ is the angular rate of disk rotation. At the same time, data of electrochemical studies are in good agreement with the

\begin{tabular}{|c|c|c|c|c|}
\hline \multirow{2}{*}{$C_{\text {Fe(III) }}, \mathrm{M}$} & \multicolumn{2}{|c|}{$2.0 \mathrm{M} \mathrm{H}_{2} \mathrm{SO}_{4}$} & \multicolumn{2}{|c|}{$2.0 \mathrm{M} \mathrm{H}_{3} \mathrm{PO}_{4}$} \\
\hline & $k$ & $\Delta k$ & $k$ & $\Delta k$ \\
\hline 0 & 9.8 & 0 & 7.8 & 0 \\
\hline 0.02 & 12 & 2.2 & 7.9 & 0.1 \\
\hline 0.05 & 15 & 5.2 & 8.2 & 0.4 \\
\hline 0.10 & 18 & 8.2 & 9.7 & 1.9 \\
\hline
\end{tabular}
results of corrosion studies based on the mass loss of metal samples, according to which an increase in the Fe(III) content in an acid solution accelerates steel corrosion (Table 5).

Table 5. Effect of $\mathrm{Fe}(\mathrm{III})$ cations on the corrosion rate $\left(k, \mathrm{~g} /\left(\mathrm{m}^{2} \cdot \mathrm{h}\right)\right)$ and the corrosion loss increment $(\Delta k$, $\mathrm{g} /\left(\mathrm{m}^{2} \cdot \mathrm{h}\right)$ ) of steel 08PS in Fe(III)-containing 2.0 $\mathrm{M} \mathrm{H}_{2} \mathrm{SO}_{4}$ and $2.0 \mathrm{M} \mathrm{H}_{3} \mathrm{PO}_{4}$. Test duration $-2 \mathrm{~h} . t=20^{\circ} \mathrm{C}$. 
The accelerating effect of $\mathrm{Fe}(\mathrm{III})$ cations on the cathodic reaction of low-carbon steels and, as a consequence, on their general corrosion is more pronounced in $\mathrm{H}_{2} \mathrm{SO}_{4}$ than in $\mathrm{H}_{3} \mathrm{PO}_{4}$ solutions [75]. The observed effect results from stronger binding of $\mathrm{Fe}(\mathrm{III})$ into complexes by phosphate anions than by sulfate anions (Table 3 ). It decreases their oxidizing ability and their mobility in a corrosive environment, which is especially important for reactions that occur in diffusion mode. A clear illustration of this situation is provided by a simulation of the plots of the Fe(III) reduction current versus the rotation rate of a steel disk (Figure 8) using Eq. (32) and the $D_{\mathrm{Fe}(\mathrm{III})}$ value measured by cyclic voltammetry on a $\mathrm{Pt}$ electrode in $\mathrm{H}_{2} \mathrm{SO}_{4}$ and $\mathrm{H}_{3} \mathrm{PO}_{4}$ solutions (Figure 2). A good agreement between experimental and theoretical data is observed, while the reduction currents of $\mathrm{Fe}(\mathrm{III})$ cations in the $\mathrm{H}_{2} \mathrm{SO}_{4}$ solution are higher than those in $\mathrm{H}_{3} \mathrm{PO}_{4}$.

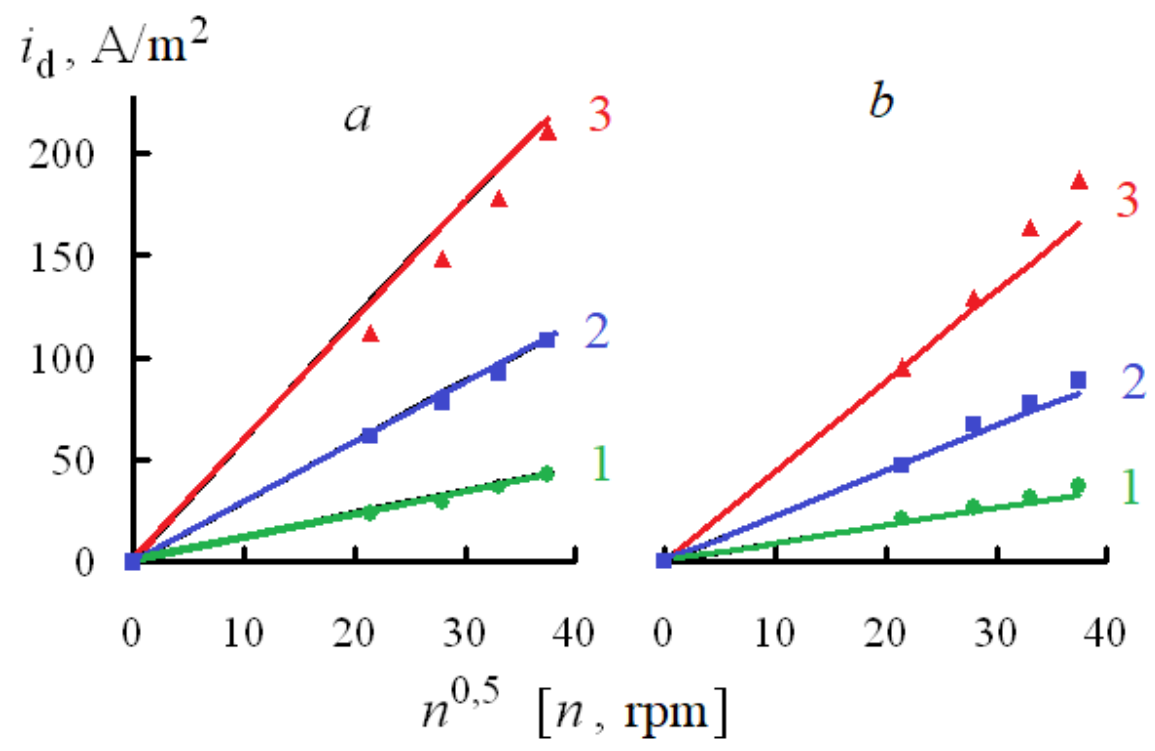

Figure 8. Dependence of the cathodic current density at $E=-0.30 \mathrm{~V}$ on the square root of the rotational speed of the disk electrode (steel 3) in $2.0 \mathrm{M} \mathrm{H}_{2} \mathrm{SO}_{4}(a)$ and $2.0 \mathrm{M} \mathrm{H}_{3} \mathrm{PO}_{4}(b)$ in the presence of $\mathrm{Fe}(\mathrm{III})(\mathrm{mol} / \mathrm{L}): 1-0.00,2-0.01,3-0.02,4-0.05,5-0.10 . t=25^{\circ} \mathrm{C}$.

Under certain conditions, Fe(III) salts present in acid solutions can act as steel passivators [76]. The reduction of oxidants on an electrically conductive passive oxide covering a steel can occur like on a steel surface free from oxide films. As a result, a steel can spontaneously remain in a stable passive state if its $E_{\text {cor }}$ is more positive than the steel passivation potential $\left(E_{\mathrm{pas}}\right)$. For spontaneous passivation of steel, the $E_{\mathrm{pas}}$ of steel has to be more negative than the equilibrium redox potential of the oxidizing agent $\left(E_{\mathrm{Ox} / \mathrm{Red}}\right)$, although this requirement is necessary but insufficient. Sufficient conditions for the passivation of metals are demonstrated in Figure 9. Depending on the position of the cathodic polarization curves (PC) of oxidant reduction (2-5), four cases of metal corrosion are possible:

a) the corrosion potential $E_{1}$ is in the area of active metal dissolution and the latter is not passivated spontaneously (curve 2); 
b) the metal is in the passive state at $E_{\text {cor }}=E_{2}$, but it is required for the onset of spontaneous passivation that at the primary passivation potential $E_{\mathrm{pp}}$, the current density of oxidant reduction $\left(i_{\mathrm{Ox}}\right)$ has to be higher than the critical current density of passivation $i_{\text {cor }}$ (curve 3 );

c) the metal corrodes at a high rate in the stable active state at $E_{\text {cor }}=E_{3}$ or in an unstable passive state at $E_{\text {cor }}=E_{4}$ in the case of its preliminary passivation by anodic polarization (curve 4);

d) the metal undergoes trans-passivation (curve 5). This case is observed if $E_{\text {cor }}=E_{5}$ where $E_{\mathrm{Ox} / \mathrm{Red}}$ is more positive than the potential of the onset of trans-passivation and the oxidant reduction occurs with insignificant inhibition.

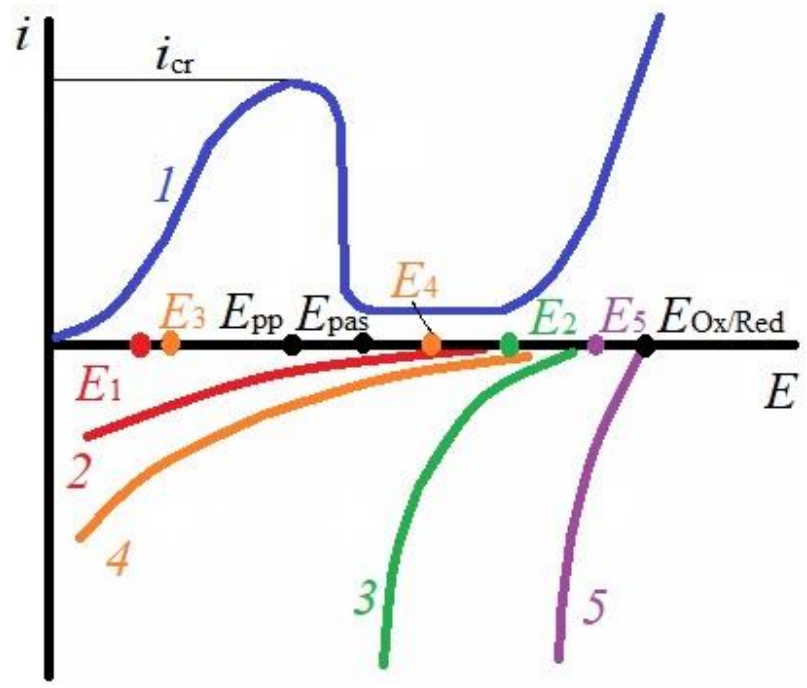

Figure 9. Scheme of establishing the corrosion potential of a passivating metal depending on the position of the cathodic partial polarization curves of a oxidant reduction (2-5) for the case when the metal can dissolve in the state of transpassivation and the equilibrium potential of the conjugated cathodic reaction $\left(\mathrm{E}_{\mathrm{ox} / \mathrm{Red}}\right)$ is more positive than the potential of the onset of transpassivation. 1 - anodic partial polarization curve of the metal.

While analyzing the effect of the addition of $\mathrm{Fe}_{2}\left(\mathrm{SO}_{4}\right)_{3}$ on stainless steel 410 in $\mathrm{H}_{2} \mathrm{SO}_{4}$ solutions, Kaesche [76] suggested a scheme illustrating its passivating action (Figure 10). Curve 1 denotes the partial anodic PC of dissolution of a rotating cylindrical steel sample; curve 2 is the partial cathodic PC of hydrogen evolution on it in a deaerated acid solution. Under these conditions, the metal is in active state at $E_{\text {cor }}=E_{1}$. Addition of $\mathrm{Fe}_{2}\left(\mathrm{SO}_{4}\right)_{3}$ to the solution in such an amount that the limiting diffusion current density of its reduction $\left(i_{\mathrm{lim}}\right)$ is smaller than $i_{\text {cor }}$ slightly shifts $E_{\text {cor }}$ in the positive direction to $E_{2}$ and $E_{3}$, but the metal remains in the active state (curves 3 and 4 ). It is only an increase in the $\mathrm{Fe}_{2}\left(\mathrm{SO}_{4}\right)_{3}$ content to values where $i_{\text {lim }}$ is higher than $i_{\text {cor }}$ that an abrupt shift of $E_{\text {cor }}$ to $E_{4}$ in the passive region occurs (curve 5). It is noted that steel can be transferred to the passive state if $i_{\text {lim }}$ is less than $i_{\text {cor. }}$. If a certain content of $\mathrm{Fe}_{2}\left(\mathrm{SO}_{4}\right)_{3}$ is insufficient for steel passivation at a low rotation rate of the sample, it can be achieved by increasing the rotation rate. 


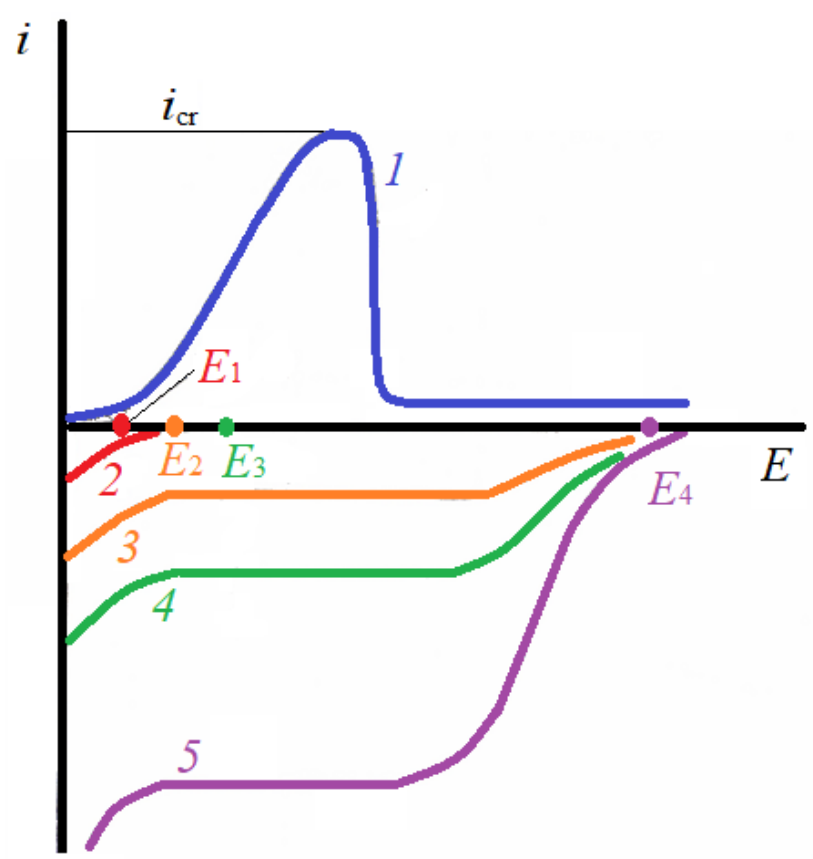

Figure 10. Schematic polarization diagram illustrating the increase of the corrosion potential of steel by increasing of the $\mathrm{Fe}_{2}\left(\mathrm{SO}_{4}\right)_{3}$ content in $\mathrm{H}_{2} \mathrm{SO}_{4}$ solutions.

The etching rate of Duplex Stainless Steel 2205 in $\mathrm{H}_{2} \mathrm{SO}_{4}$ solutions was found to slow down in the case of $\mathrm{Fe}(\mathrm{III})$ accumulation [77]. In contrast, addition of $\mathrm{HCl}$ to a $0.54 \mathrm{M}$ $\mathrm{FeCl}_{3}+0.27 \mathrm{M} \mathrm{FeCl}_{2}$ solution accelerates the corrosion of hot-rolled stainless steel 304 in this solution. It is noted that the corrosion of steel in such media occurs in the active dissolution region [78]. The corrosion of carbon steel [79] and stainless steel 304 [80] accelerates with an increase in the $\mathrm{FeCl}_{3}$ content in the solution and with an increase in $t$.

A study on the effect of $t$ on the corrosion of low-carbon steel 08PS in $2 \mathrm{M} \mathrm{HCl}$ and $\mathrm{H}_{2} \mathrm{SO}_{4}$ indicated an increase in metal losses as a result of the presence of $\mathrm{FeCl}_{3}$ and $\mathrm{Fe}_{2}\left(\mathrm{SO}_{4}\right)_{3}$ in them, respectively, with an increase in $t$ to $80^{\circ} \mathrm{C}$ [81]. In these cases, the fraction of corrosion losses of steel decreases with an increase in $t$ due to the presence of $\mathrm{Fe}$ (III) salts in the acid solutions.

Using low-carbon steel 08PS and high-strength steel 70S2KhA as examples, the effect of $\mathrm{Fe}$ (III) salts not only on their corrosion but also on hydrogen absorption in solutions of mineral acids $\left(\mathrm{HCl}, \mathrm{H}_{2} \mathrm{SO}_{4}\right.$ and $\left.\mathrm{H}_{3} \mathrm{PO}_{4}\right)$ and their mixtures was studied [82, 83]. Hydrogenation of steels in these environments depends on the chemical composition of the steel, the anionic composition of the corrosive solution, the concentration of Fe(III) salts in it, and $t$.

Solutions of Fe(III) salts are corrosive not only toward steels but also toward metals with a positive standard electrode potential that are resistant to aqueous media. Corrosion of copper, silver, palladium and gold was noted in such environments [65, 84].

Aqueous solutions of $\mathrm{Fe}(\mathrm{III})$ salts and acid solutions containing these salts are very corrosive toward steels. At the same time, it is noted that Fe(III) salts in solutions in contact with steels, primarily alloyed ones, can transfer the latter to a stable passive state that ensures 
protection. However, this protection method is unreliable, since as the Fe(III) content in a corrosive medium or its flow velocity near the metal surface decrease, steel can pass to an unstable passive state or even return to corrosion in the active dissolution region. This situation is extremely dangerous for industrial operation of steels. We see the solution to this problem in a search for efficient approaches to the inhibitory protection of metals in these media by organic compounds.

\section{Inhibitory protection of steel in acid solutions containing Fe(III) salts}

There are two approaches for reducing the adverse effect of Fe(III) cations on the corrosion of steels in acid solutions. The first one involves the use of additives that reduce $\mathrm{Fe}$ (III) cations to $\mathrm{Fe}(\mathrm{II})$ cations which affect the corrosion process less significantly. It was suggested to use $\mathrm{Sn}(\mathrm{II})$ salts [85] and hydrazine [86] as such additives. Addition of $15 \mathrm{~g} / \mathrm{L}$ $\mathrm{SnCl}_{2} \cdot 2 \mathrm{H}_{2} \mathrm{O}$ is recommended for the protection of steel in $5.9 \% \mathrm{HCl}+6.9 \mathrm{~g} / \mathrm{L} \mathrm{Fe}$ (III) (at $60^{\circ} \mathrm{C}$ ). It slows down steel corrosion by a factor of 18 . The poor performance of this additive is evident. It is very likely that its effect is based on the reduction of $\mathrm{Fe}$ (III) to $\mathrm{Fe}$ (II) by Sn(II) cations. As a result, the effect of the additive will be unstable due to its consumption. In addition, $\mathrm{SnCl}_{2}$ will be reduced on steel to give $\mathrm{Sn}^{0}$, producing micro-galvanic pairs on its surface, which will result in local corrosion of a steel product during its further operation. The industrial use of toxic hydrazine and its derivatives is also unacceptable for these purposes. It is more promising to protect steels in acid solutions containing Fe(III) salts by addition of corrosion inhibitors to the corrosive environment.

The issue of the inhibitory protection of steels in acid solutions is widely covered in scientific literature, as shown in a number of reviews [87-107]. Despite the practical importance of maintaining a high protective effect of CIs in acid solutions in the case of accumulation of Fe(III) salts therein, this issue was not considered in review literature. We believe that such a practically significant property of acid CI is not discussed in scientific literature due to the lack of any significant progress in the protection of steels in acid solutions where Fe(III) salts are accumulated. The recent achievements in the protection of steels by CIs in acid solutions containing Fe(III) salts are briefly considered only in a few articles [85, 108, 109].

Back in 1969, Podobaev et al. [110] who studied the effect of Fe(III) chloride on the corrosion of Armco iron in $\mathrm{HCl}$ solutions showed a complex effect of this additive on the inhibition of the metal corrosion by CIs of different groups (Table 6). The presence of Fe(III) chloride in inhibited corrosive media not only favors a significant acceleration of general corrosion but can, in media containing propargyl alcohol and the BA-6 inhibitor, favor the evolution of gaseous hydrogen on Armco iron. The addition of $\mathrm{FeCl}_{3}$ to inhibited acids increases $E_{\text {cor }}$ significantly. The accelerating effect of $\mathrm{FeCl}_{3}$ on the general corrosion of Armco iron is more pronounced in inhibited corrosive media, while a similar effect of nitrobenzene, an organic corrosion stimulant studied in parallel, is more pronounced in the background solutions. 
Table 6. Influence of oxidants on the corrosion parameters of a rotating disk samples of Armco iron $(n=$ $3000 \mathrm{rpm}$ ) in $10 \mathrm{M} \mathrm{HCl}$. Test duration $-0.25 \mathrm{~h} . t=20^{\circ} \mathrm{C}$.

\begin{tabular}{|c|c|c|c|c|}
\hline \multirow[b]{2}{*}{ Oxidant } & \multicolumn{4}{|c|}{ Inhibitor } \\
\hline & - & $5 \mathrm{mM} \mathrm{KI}$ & $\begin{array}{c}5 \text { mM propargyl } \\
\text { alcohol }\end{array}$ & $0.25 \%$ BA-6 \\
\hline \multicolumn{5}{|c|}{ Corrosion potential, $\mathrm{V}$} \\
\hline- & -0.21 & -0.22 & -0.22 & -0.22 \\
\hline $5 \mathrm{mM}$ nitrobenzene & -0.19 & -0.16 & -0.15 & -0.19 \\
\hline $20 \mathrm{mM} \mathrm{FeCl}_{3}$ & -0.20 & -0.19 & -0.18 & -0.07 \\
\hline \multicolumn{5}{|c|}{ The volume of hydrogen evolved during the experiment, $\mathrm{mL}$} \\
\hline- & 8.6 & 2.6 & - & - \\
\hline $5 \mathrm{mM}$ nitrobenzene & - & 3.0 & - & - \\
\hline $20 \mathrm{mM} \mathrm{FeCl}_{3}$ & 8.1 & 2.8 & 1.6 & 1.2 \\
\hline \multicolumn{5}{|c|}{ Corrosion rate, $\mathrm{g} /\left(\mathrm{m}^{2} \cdot \mathrm{h}\right)$} \\
\hline- & 114 & 29 & 8.4 & 3.0 \\
\hline $5 \mathrm{mM}$ nitrobenzene & 188 & 86 & 38 & 3.6 \\
\hline $20 \mathrm{mM} \mathrm{FeCl}_{3}$ & 175 & 108 & 96 & 72 \\
\hline
\end{tabular}

Industrial CIs and their mixtures poorly protect steel 10 and steel EI 531 in $4 \% \mathrm{HCl}$ $\left(60-80^{\circ} \mathrm{C}\right)$ containing $\mathrm{FeCl}_{3}$ (Table 7). Even in the presence of the most efficient mixtures (PB-5 + OP-10 + urotropine or PB-5 + urotropine), the $k$ value of steel 10 is $\leq 9.1 \mathrm{~g} /\left(\mathrm{m}^{2} \cdot \mathrm{h}\right.$ ) and that of steel EI 531 is $\leq 7.7 \mathrm{~g} /\left(\mathrm{m}^{2} \cdot \mathrm{h}\right)$ [111]. In the same hydrochloric acid solution containing mixed CIs (PB-5 + urotropine or catapin KI-1 + urotropine), acceleration of steel 20 corrosion with an increase in the content of $\mathrm{FeCl}_{3}$ is observed. Corrosion of steel also increases on transition from static to dynamic experimental conditions, which is typical of processes that occur under diffusion control (Table 8). The variation in $C_{\mathrm{Fe}(\mathrm{III})}$ and total $C_{\mathrm{Fe}(\mathrm{III})+\mathrm{Fe} \text { (II) }}$ in a corrosive medium in contact with steel obeys certain regularities (Figure 11). The Fe(III) content decreases with time the more abruptly, the higher the initial $C_{\mathrm{Fe}(\mathrm{III})}$ and solution temperature, as well as in case of solution circulation. The growth in the total content of $\mathrm{Fe}(\mathrm{III})+\mathrm{Fe}$ (II) ions follows the same regularities. In the presence of a CI, the decrease in $C_{\mathrm{Fe}(\mathrm{III})}$ in a solution and the increase in $C_{\mathrm{Fe}(\mathrm{III})+\mathrm{Fe} \text { (II) }}$ occur to a lesser extent than without a $\mathrm{CI}$ in the background solution. The corrosion rate of steel due to reaction (15) in a solution containing a CI decreases in the first hour more sharply than without it (Figure 12). In an inhibited medium, a residual content of Fe(III) ions is observed at the end of the experiment, which indicates that reaction (15) continues at a low rate. In a solution without a $\mathrm{CI}$, the oxidation of steel by Fe(III) ions occurs more intensely in the first hour and then ceases. 
In general, though CIs have high protective effects in some cases, the corrosion rates of steel in the media in question are high, especially in tests in a stream of a corrosive medium [112].
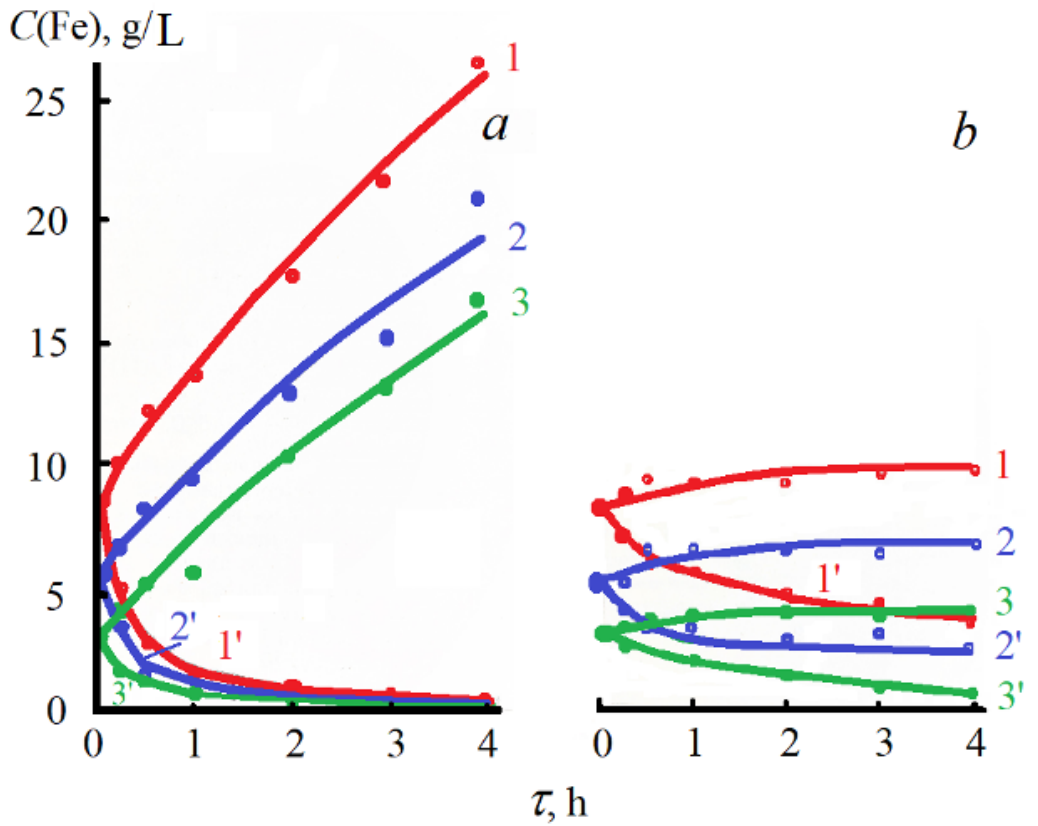

Figure 11. The mass concentration of $\mathrm{Fe}(\mathrm{III})$ ions $\left(1^{\prime}-3\right)$ and the total content of $\mathrm{Fe}(\mathrm{III})+$ $\mathrm{Fe}(\mathrm{II})$ ions $(1-3)$ during corrosion of steel 20 in static $4 \% \mathrm{HCl}$ at the initial content of $\mathrm{Fe}(\mathrm{III})$ ions, $\%: 1,1^{\prime}-0.8,2,2^{\prime}-0.5,3,3^{\prime}-0.3 . a-$ without inhibitor, $b-0.2 \%$ PB-5 $+0.5 \%$ urotropine. $t=60^{\circ} \mathrm{C}$.
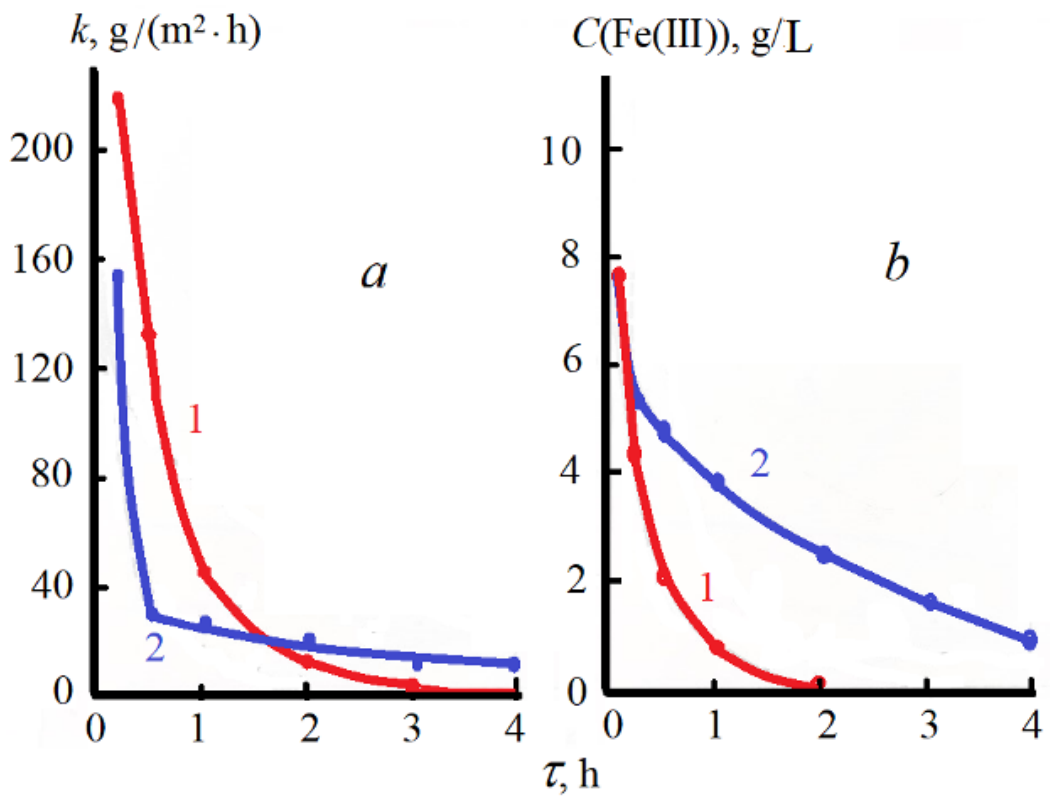

Figure 12. The corrosion rate of steel 20 as a result of the reaction $\mathrm{Fe}+2 \mathrm{Fe}^{3+}=3 \mathrm{Fe}^{2+}(a)$ and the content of $\mathrm{Fe}(\mathrm{III})$ ions $(b)$ in $4 \% \mathrm{HCl}+0.8 \% \mathrm{Fe}$ (III). $a$ - without an inhibitor, $b-0.2 \%$ PB-5 $+0.5 \%$ urotropine. $t=80^{\circ} \mathrm{C}$, fluid flow velocity $-1 \mathrm{~m} / \mathrm{s}$. 
Table 7.* Corrosion rates $\left(k, \mathrm{~g} /\left(\mathrm{m}^{2} \cdot \mathrm{h}\right)\right)$ and corrosion inhibition coefficients $(\gamma)$ of steel 10 and steel EI 531 in $4 \% \mathrm{HCl}$ containing $\mathrm{FeCl}_{3}$. Test duration $-4 \mathrm{~h}$. Fluid flow velocity $-1 \mathrm{~m} / \mathrm{s}$.

Content of $\mathrm{Fe}(\mathrm{III})$ cations, $\mathrm{g} / \mathrm{L}$

\begin{tabular}{|c|c|c|c|c|c|c|}
\hline \multirow[t]{2}{*}{ Inhibitor } & \multicolumn{2}{|c|}{0.5} & \multicolumn{2}{|c|}{1.0} & \multicolumn{2}{|c|}{2.0} \\
\hline & $k$ & $\gamma$ & $k$ & $\gamma$ & $k$ & $\gamma$ \\
\hline \multicolumn{7}{|c|}{ Steel $10,60^{\circ} \mathrm{C}$} \\
\hline- & 56.0 & - & 78.9 & - & 127.5 & - \\
\hline $1 \%$ urotropine & 43.7 & 1.3 & 65.7 & 1.2 & 109.0 & 1.2 \\
\hline $0.5 \%$ PB-5 & 21.2 & 2.6 & 47.0 & 1.7 & 79.7 & 1.6 \\
\hline $\begin{array}{c}0.5 \% \mathrm{~PB}-5+0.5 \% \\
\text { urotropine }\end{array}$ & 9.4 & 5.2 & 12.4 & 6.3 & 41.8 & 3.0 \\
\hline $\begin{array}{c}0.5 \% \text { PB- } 5+0.5 \% \\
\text { urotropine }+0.3 \% \\
\text { OP-10 }\end{array}$ & 9.1 & 6.1 & 14.4 & 5.5 & 34.1 & 3.7 \\
\hline $0.5 \%$ SA-U & 22.3 & 2.5 & 37.3 & 2.1 & 76.7 & 1.7 \\
\hline \multicolumn{7}{|c|}{ Steel $10,80^{\circ} \mathrm{C}$} \\
\hline- & 102.0 & - & 151.0 & - & 223.0 & - \\
\hline $1 \%$ urotropine & 63.5 & 1.6 & 76.6 & 2.0 & 218.0 & 1.0 \\
\hline $0.5 \%$ PB-5 & 20.6 & 4.9 & 45.0 & 3.4 & 85.0 & 2.6 \\
\hline $\begin{array}{c}0.5 \% \text { PB- } 5+0.5 \% \\
\text { urotropine }\end{array}$ & 12.7 & 8.0 & 17.8 & 8.5 & 51.7 & 4.3 \\
\hline $\begin{array}{c}0.5 \% \text { PB- } 5+0.5 \% \\
\text { urotropine }+0.3 \% \\
\text { OP-10 }\end{array}$ & 11.0 & 9.3 & 17.1 & 8.8 & 31.1 & 7.1 \\
\hline $0.5 \%$ SA-U & 15.2 & 6.7 & 21.3 & 7.1 & 32.2 & 6.9 \\
\hline \multicolumn{7}{|c|}{ Steel EI $531,60^{\circ} \mathrm{C}$} \\
\hline- & 52.2 & - & 99.3 & - & 199.0 & - \\
\hline $1 \%$ urotropine & 50.0 & 1.0 & 94.0 & 1.1 & 185.0 & 1.1 \\
\hline $0.5 \%$ PB-5 & 25.7 & 2.0 & 62.0 & 1.6 & 138.5 & 1.4 \\
\hline $\begin{array}{c}0.5 \% \mathrm{~PB}-5+0.5 \% \\
\text { urotropine }\end{array}$ & 7.7 & 6.8 & 33.3 & 3.0 & 106.2 & 1.9 \\
\hline $\begin{array}{c}0.5 \% \text { PB- } 5+0.5 \% \\
\text { urotropine }+0.3 \% \\
\text { OP-10 }\end{array}$ & 11.5 & 4.5 & 35.2 & 2.8 & 89.0 & 2.2 \\
\hline $0.5 \%$ SA-U & 18.8 & 2.8 & 49.5 & 2.0 & 107.5 & 1.8 \\
\hline
\end{tabular}




\begin{tabular}{|c|c|c|c|c|c|c|}
\hline \multirow{3}{*}{ Inhibitor } & \multicolumn{6}{|c|}{ Content of $\mathrm{Fe}(\mathrm{III})$ cations, g/L } \\
\hline & \multicolumn{2}{|c|}{0.5} & \multicolumn{2}{|c|}{1.0} & \multicolumn{2}{|c|}{2.0} \\
\hline & $\boldsymbol{k}$ & $\gamma$ & $\boldsymbol{k}$ & $\gamma$ & $\boldsymbol{k}$ & $\gamma$ \\
\hline \multicolumn{7}{|c|}{ Steel EI $531,80^{\circ} \mathrm{C}$} \\
\hline- & 84.5 & - & 131.0 & - & 276.0 & - \\
\hline $1 \%$ urotropine & 77.0 & 1.1 & 128.0 & 1.0 & 225.0 & 1.2 \\
\hline $0.5 \%$ PB-5 & 19.4 & 4.3 & 72.5 & 1.8 & 171.2 & 1.6 \\
\hline $\begin{array}{c}0.5 \% \mathrm{~PB}-5+0.5 \% \\
\text { urotropine }\end{array}$ & 9.0 & 9.4 & 39.5 & 3.3 & 105.2 & 2.6 \\
\hline $\begin{array}{c}0.5 \% \text { PB- } 5+0.5 \% \\
\text { urotropine }+0.3 \% \\
\text { OP-10 }\end{array}$ & 14.1 & 6.0 & 32.4 & 4.0 & 73.8 & 3.7 \\
\hline $0.5 \%$ SA-U & 14.4 & 5.8 & 19.4 & 6.7 & 73.2 & 3.8 \\
\hline
\end{tabular}

* The corrosion rate of steel 10 in $4 \% \mathrm{HCl}$ at 60 and $80^{\circ} \mathrm{C}$ is 18.5 and $38.4 \mathrm{~g} /\left(\mathrm{m}^{2} \cdot \mathrm{h}\right)$. steel EI $531-11.0$ and $30.6 \mathrm{~g} /\left(\mathrm{m}^{2} \cdot \mathrm{h}\right)$.

Table 8. Corrosion rates $\left(k, \mathrm{~g} /\left(\mathrm{m}^{2} \cdot \mathrm{h}\right)\right)$ and degree of protection $(Z, \%)$ of steel 20 in $4 \% \mathrm{HCl}$ containing $\mathrm{FeCl}_{3}$. Test duration $-4 \mathrm{~h}$.

\begin{tabular}{|c|c|c|c|c|c|c|c|c|}
\hline \multirow{3}{*}{$\begin{array}{c}\text { Content } \\
\text { of } \mathrm{Fe}(\mathrm{III}) \\
\text { cations, \% }\end{array}$} & \multicolumn{4}{|c|}{ Static condition } & \multicolumn{4}{|c|}{ Fluid flow velocity $-1 \mathrm{~m} / \mathrm{s}$} \\
\hline & \multicolumn{2}{|c|}{$60^{\circ} \mathrm{C}$} & \multicolumn{2}{|c|}{$80^{\circ} \mathrm{C}$} & \multicolumn{2}{|c|}{$60^{\circ} \mathrm{C}$} & \multicolumn{2}{|c|}{$80^{\circ} \mathrm{C}$} \\
\hline & $\boldsymbol{k}$ & $Z$ & $\boldsymbol{k}$ & $Z$ & $\boldsymbol{k}$ & $Z$ & $\boldsymbol{k}$ & $Z$ \\
\hline \multicolumn{9}{|c|}{ Without inhibitor } \\
\hline 0 & 50 & - & 195 & - & 27 & - & 68 & - \\
\hline 0.3 & 107 & - & 245 & - & 122 & - & 456 & - \\
\hline 0.5 & 125 & - & 257 & - & 195 & - & 698 & - \\
\hline 0.8 & 140 & - & 275 & - & 303 & - & 876 & - \\
\hline \multicolumn{9}{|c|}{$0.2 \% \mathrm{~PB}-5+0.5 \%$ urotropine } \\
\hline 0 & 0.6 & 98.8 & 4.3 & 97.8 & 5.4 & 80.0 & 3.4 & 95.0 \\
\hline 0.3 & 5.8 & 94.6 & 7.6 & 96.9 & 25.0 & 79.5 & 21.9 & 95.2 \\
\hline 0.5 & 7.0 & 94.4 & 12.1 & 95.3 & 55.1 & 71.8 & 44.7 & 93.6 \\
\hline 0.8 & 11.6 & 91.7 & 19.8 & 92.8 & 89.5 & 70.5 & 64.8 & 92.6 \\
\hline
\end{tabular}




\begin{tabular}{|c|c|c|c|c|c|c|c|c|}
\hline \multirow{3}{*}{$\begin{array}{c}\text { Content } \\
\text { of Fe(III) } \\
\text { cations, \% }\end{array}$} & \multicolumn{4}{|c|}{ Static condition } & \multicolumn{4}{|c|}{ Fluid flow velocity $-1 \mathrm{~m} / \mathrm{s}$} \\
\hline & \multicolumn{2}{|c|}{$60^{\circ} \mathrm{C}$} & \multicolumn{2}{|c|}{$80^{\circ} \mathrm{C}$} & \multicolumn{2}{|c|}{$60^{\circ} \mathrm{C}$} & \multicolumn{2}{|c|}{$80^{\circ} \mathrm{C}$} \\
\hline & $\boldsymbol{k}$ & $Z$ & $\boldsymbol{k}$ & $Z$ & $\boldsymbol{k}$ & $Z$ & $\boldsymbol{k}$ & $Z$ \\
\hline \multicolumn{9}{|c|}{$0.1 \%$ Catapine $\mathrm{KI}-1+0.5 \%$ urotropine } \\
\hline 0 & 1.5 & 97.0 & 1.3 & 99.4 & 7.5 & 72.2 & 6.8 & 90.0 \\
\hline 0.3 & 6.2 & 94.2 & 11.9 & 95.2 & 41.5 & 66.1 & 43.9 & 91.3 \\
\hline 0.5 & 9.4 & 92.6 & 15.3 & 94.1 & 70.4 & 64.0 & 75.8 & 89.1 \\
\hline 0.8 & 12.3 & 91.2 & 28.2 & 89.8 & 101.5 & 66.6 & 106.8 & 87.9 \\
\hline
\end{tabular}

Back in 1969, Balezin et al. [113] reported results of a search for CIs for steel 20 in $0.5 \mathrm{~N}$ citric acid $\left(80-100^{\circ} \mathrm{C}\right)$. The most interesting results on steel protection in this environment are provided by binary formulations: catapin $\mathrm{K}+$ captax and catapin $\mathrm{K}+\mathrm{SnCl}_{2}$. However, the presence of $\mathrm{Fe}(\mathrm{II})$ and $\mathrm{Fe}(\mathrm{III})$ citrates in this inhibited medium, either in individual form or as a mixture, can significantly accelerate the corrosion of steel, especially in a moving corrosive environment (Table 9). In static $0.5 \mathrm{~N}$ citric acid containing $\mathrm{Fe}(\mathrm{II})$ and $\mathrm{Fe}(\mathrm{III})$ citrates, the three-component mixture catapin $\mathrm{K}+$ captax $+\mathrm{SnCl}_{2}$ provides good protection, but it is also inefficient in a stream of the corrosive medium. One has to bear in mind the low performance of composite CIs containing $\mathrm{Sn}$ (II) that will be removed from an acid solution due to a reaction with steel to form undesirable metallic tin on its surface, along with oxidation with $\mathrm{Fe}(\mathrm{III})$ cations.

Table 9. Corrosion rates $\left(k, \mathrm{~g} /\left(\mathrm{m}^{2} \cdot \mathrm{h}\right)\right)$ of steel 20 in $0.5 \mathrm{~N}$ citric acid, containing Fe citrates. Test duration 2 h. $t=100^{\circ} \mathrm{C}$.

\section{Inhibitor}

Additives of Fe citrates

\begin{tabular}{ccc}
\hline \multicolumn{3}{c}{$0.1 \%$ Catapine K } \\
\hline $\begin{array}{c}\text { 0.03\% } \\
\text { Captax }\end{array}$ & $0.1 \% \mathrm{SnCl}_{2}$ & $\begin{array}{l}0.03 \% \text { Captax } \\
+0.1 \% \mathrm{SnCl}_{2}\end{array}$
\end{tabular}

Static conditions*

\begin{tabular}{cccc}
\hline Without Fe citrates & 0.32 & 0,27 & - \\
$2 \mathrm{~g} / \mathrm{L} \mathrm{Fe}(\mathrm{II})$ citrate & 0.47 & 4.0 & - \\
$2 \mathrm{~g} / \mathrm{L} \mathrm{Fe}(\mathrm{III})$ citrate & 4.2 & 0.39 & - \\
\hline $\mathrm{g} / \mathrm{L} \mathrm{Fe}(\mathrm{II})$ citrate $+2 \mathrm{~g} / \mathrm{L} \mathrm{Fe}(\mathrm{III})$ citrate & 11 & 7.6 & 1.6 \\
\hline Fluid flow velocity $-1 \mathrm{~m} / \mathrm{s}$ & & \\
\hline $2 \mathrm{~g} / \mathrm{L} \mathrm{Fe}(\mathrm{II})$ citrate $+2 \mathrm{~g} / \mathrm{L} \mathrm{Fe}(\mathrm{III})$ citrate & 59 & 46 & 8.4 \\
\hline
\end{tabular}

* The corrosion rate of steel 20 in $0.5 \mathrm{~N}$ citric acid is $80.2 \mathrm{~g} /\left(\mathrm{m}^{2} \cdot \mathrm{h}\right)$. 
One can see from the above data that it is nearly impossible to provide efficient protection of steels with CIs in solutions of mineral and organic acids containing $\mathrm{Fe}$ (III) salts. This conclusion is confirmed by our data, according to which none of the nine industrial CIs studied (Soling m. Z, Soling m. L, VNPP-2, INVOL-2 m. A, NORUST CM $150 \mathrm{C}$, PKU-E, catapin A, catapin BPV, and catamine AB) can efficiently protect steel 08PS in solutions of $\mathrm{HCl}, \mathrm{H}_{2} \mathrm{SO}_{4}$, or $\mathrm{H}_{3} \mathrm{PO}_{4}$ in the presence of the corresponding $\mathrm{Fe}$ (III) salts [39].

Let us consider the reasons for the decrease in the CI efficiency in the corrosion of steels in acid solutions. According to Antropov [114], addition of Fe(III) cations to a corrosive medium shifts the $E_{\text {cor }}$ of steels to higher potentials, which increases the positive charge of the metal surface. This complicates or makes impossible the adsorption of cationic CIs on them since their particles are charged positively. Such a change in the adsorbability of these compounds is the reason for the decrease or complete cessation of their protective action. Moreover, the reduction of Fe(III) cations occurs in diffusion mode, and the CI efficiency may weaken due to a low degree of surface screening that plays a decisive role in the inhibition of corrosion processes. Indeed, our later studies using a rotating disk electrode $[115,116]$ showed that the low protection of steels by organic CIs in acids containing $\mathrm{Fe}$ (III) primarily results from the weak inhibition of cathodic reaction (31) by these CIs. In addition, the presence of $\mathrm{Fe}$ (III) salts in a corrosive environment is often capable of causing the coagulation of organic CIs present in it, which removes them from the corrosive environment [115]. We believe that each of the factors mentioned above can determine the low efficiency of a CI. In many cases, it can be the result of their joint effect.

It is interesting that in acidic media containing Fe(III) salts, the inhibitory protection of not only steels but also copper encounters difficulties, especially at high $C_{\mathrm{Fe}(\mathrm{III})}[117,118]$.

A fundamentally new approach to the protection of steels in acid solutions containing $\mathrm{Fe}(\mathrm{III})$ was developed by discovering that inhibitory protection of steel 3 in solutions of $\mathrm{H}_{3} \mathrm{PO}_{4}+\mathrm{FePO}_{4}$ is possible $[115,116]$. It has been shown that addition of the composite inhibitor IFKhAN-92 + KNCS slows down the corrosion of steel 3 considerably even if significant amounts of $\mathrm{Fe}$ (II) and, especially important, $\mathrm{Fe}(\mathrm{III})$ are accumulated in the corrosive environment (Table 10). It is important that in $2 \mathrm{M} \mathrm{H}_{3} \mathrm{PO}_{4}+0.1 \mathrm{M} \mathrm{FePO}_{4}(25-$ $95^{\circ} \mathrm{C}$ ) inhibited by $5.0 \mathrm{mM}$ IFKhAN-92 $+0.5 \mathrm{mM} \mathrm{KNCS}$, the values of $k$ for steel 3 are very low, $\geq 2.3 \mathrm{~g} /\left(\mathrm{m}^{2} \cdot \mathrm{h}\right)$. The composite CI slows down the cathodic and anodic processes on steel significantly (Figure 13), while both cathodic partial reactions (19) and (31) are inhibited, as indicated by the nature of the plot of the cathodic reaction rate $v s$. the rotation frequency of the steel disk electrode (Figure 14).

The efficient inhibition of partial electrode reactions of steel by this CI results from the formation of a protective polymolecular layer from chemically bound triazole molecules, thiocyanate anions, and $\mathrm{Fe}$ (II) cations on its surface through coordination interaction. Its thickness is at least 4 conventional monomolecular layers. In turn, this protective layer is chemically bound to the steel surface. The formation of a protective layer on the steel surface by the mixed CI is confirmed by data of its X-ray photoelectron spectroscopy, according to which the spectrum of $\mathrm{N}$ atoms contains two signals (399.5 and $401.4 \mathrm{eV}$ ) (Figure 15). The 
first peak is due to the $\mathrm{N}$ atoms of the IFKhAN-92 molecule's triazole ring and the nitrogen atoms of the thiocyanate anion. The second peak is determined by the nitrogen atom of the IFKhAN-92 molecule outside the triazole ring [116].

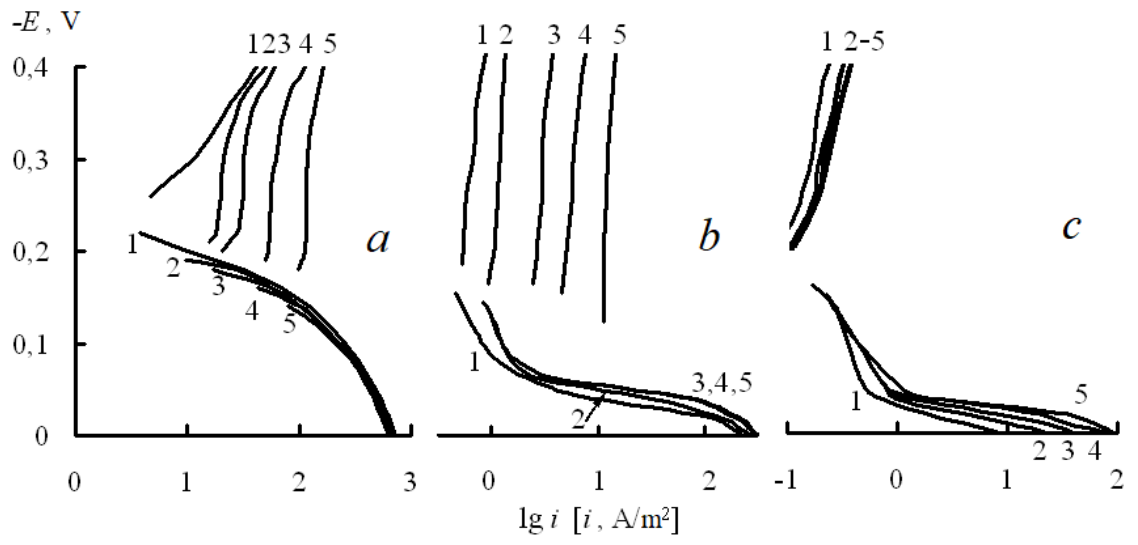

Figure 13. Polarization curves of the steel 3 disk $(n=460 \mathrm{rpm})$ in $2,0 \mathrm{M} \mathrm{H}_{3} \mathrm{PO}_{4}(a)$, inhibited by $0.5 \mathrm{mM}$ IFKhAN-92 $+0.5 \mathrm{mM} \mathrm{KNCS}(b)$ and $5.0 \mathrm{mM}$ IFKhAN-92 + $0.5 \mathrm{mM} \mathrm{KNCS}(c)$, in the presence of $\mathrm{FePO}_{4}(\mathrm{~mol} / \mathrm{L}): 1-0.00,2-0.01,3-0.02,4-0.05,5-0.10 . t=25^{\circ} \mathrm{C}$.

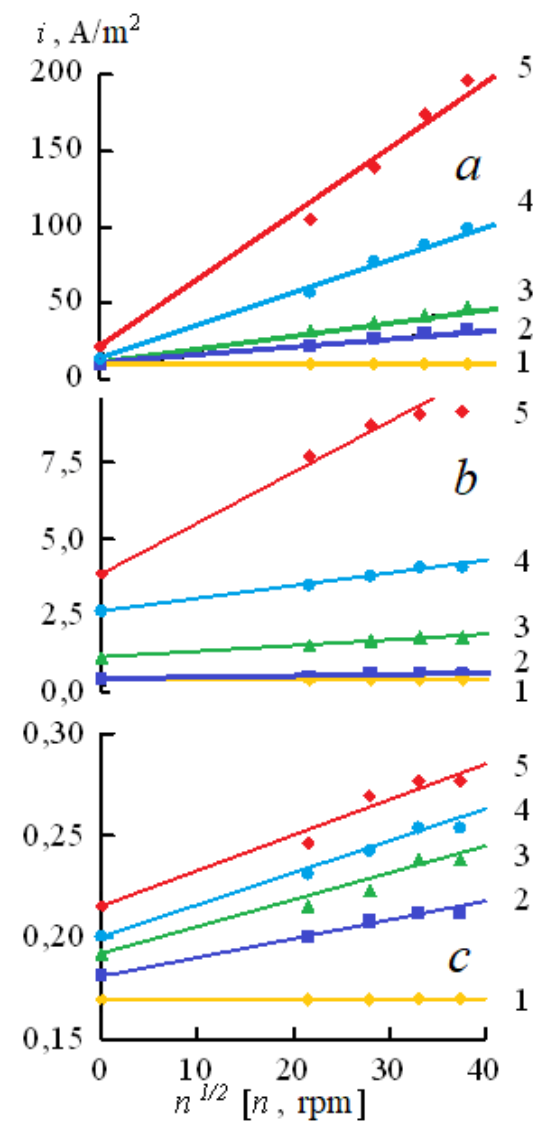

Figure 14. Dependence of the cathodic current density at $E=-0.30 \mathrm{~V}$ on the square root of the rotational speed of the disk electrode (steel 3) in $2.0 \mathrm{M} \mathrm{H}_{3} \mathrm{PO}_{4}(a)$ inhibited by $0.5 \mathrm{mM}$ IFKhAN-92+0.5 mM KNCS $(b)$ and 5.0 mM IFKhAN-92+0.5 mM KNCS $(c)$, in the presence of $\mathrm{FePO}_{4}(\mathrm{~mol} / \mathrm{L}): 1-0.00,2-0.01,3-0.02,4-0.05,5-0.10 . t=25^{\circ} \mathrm{C}$. 
Another important factor determining the high protection of steel with IFKhAN-92 in $\mathrm{H}_{3} \mathrm{PO}_{4}+\mathrm{FePO}_{4}$ solutions is that $\mathrm{Fe}(\mathrm{III})$ cations are bound in this medium into strong phosphate complexes, which significantly decreases their oxidizing ability and mobility $[45,46,61,62]$. This is the determining slowdown factor in the course of reaction (31) characterized by diffusion control in the inhibited medium.

Table 10. Influence of $\mathrm{Fe}(\mathrm{III})$ and $\mathrm{Fe}(\mathrm{II})$ cations on the inhibition corrosion of steel 3 in $2 \mathrm{M} \mathrm{H}_{3} \mathrm{PO}_{4}$ by a composition of $5.0 \mathrm{mM}$ IFKhAN-92 + 0.5 mM KNCS.

\begin{tabular}{|c|c|c|c|c|c|c|c|}
\hline \multirow{2}{*}{ Fe cations } & \multirow{2}{*}{ Inhibitor } & \multirow{2}{*}{$k, \gamma^{*}$} & \multicolumn{5}{|c|}{ Temperature, ${ }^{\circ} \mathrm{C}$} \\
\hline & & & 25 & 40 & 60 & 80 & 95 \\
\hline \multirow{3}{*}{-} & - & $k$ & 7.8 & 23.5 & 62.8 & 222 & 505 \\
\hline & $5.0 \mathrm{mM}$ IFKhAN-92 & $k$ & 0.083 & 0.28 & 0.33 & 0.52 & 1.34 \\
\hline & $+0.5 \mathrm{mM}$ KNCS & $\gamma$ & 94.0 & 83.9 & 190 & 426 & 377 \\
\hline \multirow{3}{*}{$0.01 \mathrm{M} \mathrm{Fe}(\mathrm{III})$} & - & $k$ & 7.0 & 23.0 & 65.3 & 220 & 499 \\
\hline & $5.0 \mathrm{mM}$ IFKhAN-92 & $k$ & 0.10 & 0.30 & 0.32 & 0.47 & 1.40 \\
\hline & + $0.5 \mathrm{mM} \mathrm{KNCS}$ & $\gamma$ & 70.0 & 76.7 & 204 & 468 & 356 \\
\hline \multirow{3}{*}{$0.05 \mathrm{M} \mathrm{Fe}(\mathrm{III})$} & - & $k$ & 10.5 & 26.1 & 76.0 & 232 & 508 \\
\hline & $5.0 \mathrm{mM}$ IFKhAN-92 & $k$ & 0.23 & 0.44 & 0.47 & 0.80 & 1.53 \\
\hline & $+0.5 \mathrm{mM}$ KNCS & $\gamma$ & 45.7 & 59.3 & 162 & 290 & 332 \\
\hline \multirow{3}{*}{$0.10 \mathrm{M} \mathrm{Fe}(\mathrm{III})$} & - & $k$ & 13.5 & 30.8 & 89.9 & 237 & 511 \\
\hline & $5.0 \mathrm{mM}$ IFKhAN-92 & $k$ & 0.42 & 1.76 & 2.02 & 2.10 & 2.32 \\
\hline & $+0.5 \mathrm{mM} \mathrm{KNCS}$ & $\gamma$ & 32.1 & 17.5 & 44.5 & 173 & 220 \\
\hline \multirow{3}{*}{$0.10 \mathrm{M} \mathrm{Fe}(\mathrm{II})$} & - & $k$ & 6.5 & 23.0 & 64.6 & 235 & 511 \\
\hline & $5.0 \mathrm{mM}$ IFKhAN-92 & $k$ & 0.050 & 0.13 & 0.22 & 0.28 & 1.03 \\
\hline & + $0.5 \mathrm{mM}$ KNCS & $\gamma$ & 128 & 177 & 294 & 839 & 496 \\
\hline \multirow{3}{*}{$0.50 \mathrm{M} \mathrm{Fe}(\mathrm{II})$} & - & $k$ & 6.2 & 19.2 & 67.8 & 290 & 332 \\
\hline & $5.0 \mathrm{mM}$ IFKhAN-92 & $k$ & 0.10 & 0.28 & 0.38 & 0.66 & 1.5 \\
\hline & $+0.5 \mathrm{mM} \mathrm{KNCS}$ & $\gamma$ & 62.0 & 68.6 & 178 & 439 & 221 \\
\hline \multirow{3}{*}{$1.0 \mathrm{M} \mathrm{Fe}(\mathrm{II})$} & - & $k$ & 4.9 & 19.7 & 68.3 & 117 & 98.7 \\
\hline & $5.0 \mathrm{mM}$ IFKhAN-92 & $k$ & 0.10 & 0.92 & 1.31 & 2.03 & 6.3 \\
\hline & + $0.5 \mathrm{mM} \mathrm{KNCS}$ & $\gamma$ & 49.0 & 21.4 & 52.1 & 57.6 & 15.7 \\
\hline $0.05 \mathrm{M} \mathrm{Fe}(\mathrm{III})$ & - & $k$ & 9.3 & - & 71.3 & - & - \\
\hline \multirow{2}{*}{$\begin{array}{c}+ \\
0.05 \mathrm{M} \mathrm{Fe}(\mathrm{II})\end{array}$} & $5.0 \mathrm{mM}$ IFKhAN-92 & $k$ & 0.23 & - & 0.40 & - & - \\
\hline & $+0.5 \mathrm{mM} \mathrm{KNCS}$ & $\gamma$ & 40.4 & - & 178 & - & - \\
\hline
\end{tabular}

$* \gamma=k_{0} / k_{\mathrm{in}}$, where $k_{0}$ and $k_{\text {in }}$ are the corrosion rates of steel 3 in the non-inhibited solution and in the solution with the additive being studied, respectively. 


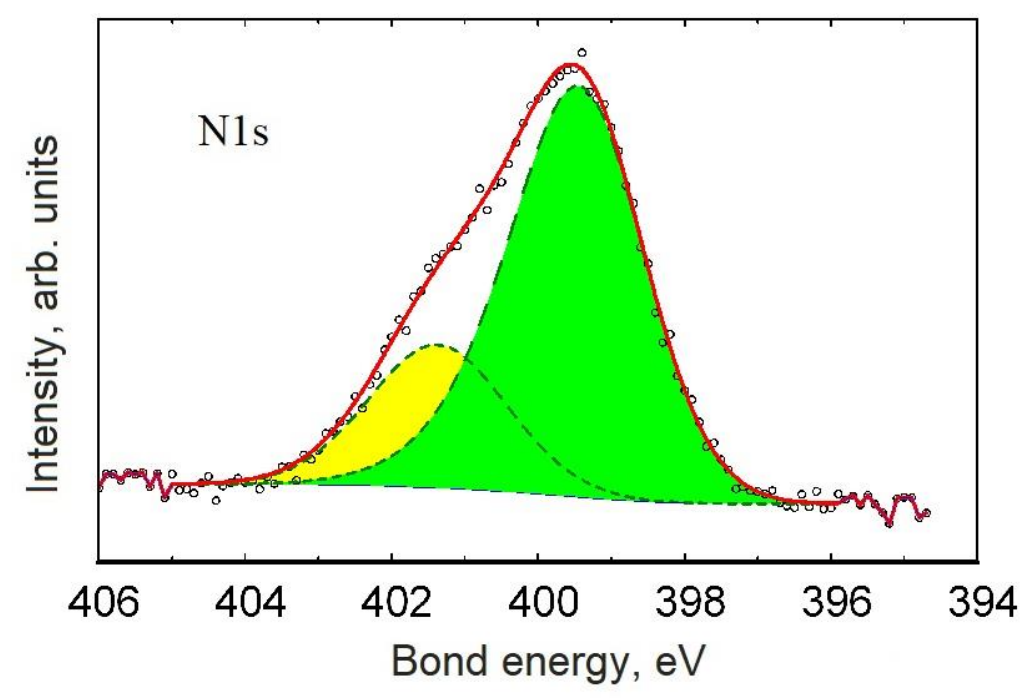

Figure 15. XPS spectra of N1s electrons of surface of steel 3 after exposure to $2 \mathrm{M} \mathrm{H}_{3} \mathrm{PO}_{4}+$ $5 \mathrm{mM}$ IFKhAN-92 + $5 \mathrm{mM} \mathrm{KNCS}\left(24 \mathrm{~h}, 25^{\circ} \mathrm{C}\right)$.

Solutions of acid mixtures $\left(\mathrm{HCl}+\mathrm{H}_{3} \mathrm{PO}_{4}\right.$ or $\left.\mathrm{H}_{2} \mathrm{SO}_{4}+\mathrm{H}_{3} \mathrm{PO}_{4}\right)$ inhibited with IFKhAN92 formulations that are cheaper than media containing $\mathrm{H}_{3} \mathrm{PO}_{4}$ alone can be promising alternatives to $\mathrm{H}_{3} \mathrm{PO}_{4}$ solutions containing the IFKhAN-92 + KNCS formulation if there is potential danger that $\mathrm{Fe}$ (III) salts can accumulate in them. An important role in the creation of such solutions is played by the fact that even in solutions of acid mixtures $\left(\mathrm{HCl}+\mathrm{H}_{3} \mathrm{PO}_{4}\right.$ or $\mathrm{H}_{2} \mathrm{SO}_{4}+\mathrm{H}_{3} \mathrm{PO}_{4}$ ), $\mathrm{Fe}(\mathrm{III})$ cations are bound into complex compounds with phosphate anions, which also reduces their oxidizing ability and mobility. This turns out to be sufficient for efficient protection of low-carbon [81, 119] and high-strength steels [82] by the binary formulation IFKhAN-92 + KNCS in a $\mathrm{H}_{2} \mathrm{SO}_{4}+\mathrm{H}_{3} \mathrm{PO}_{4}$ mixture containing up to 60 mol.\% of $\mathrm{H}_{2} \mathrm{SO}_{4}$ in case of accumulation of $\mathrm{Fe}(\mathrm{III})$ salts in the acid environment. The threecomponent mixture IFKhAN-92 + KNCS + urotropine (molar ratio of components 9:1:400) is more interesting for the protection of steels in acid environments based on $\mathrm{H}_{3} \mathrm{PO}_{4}$ and containing $\mathrm{Fe}(\mathrm{III})$ salts. It protects low-carbon $[119,120]$ and high-strength [82, 83] steels in $\mathrm{H}_{2} \mathrm{SO}_{4}+\mathrm{H}_{3} \mathrm{PO}_{4}$ and $\mathrm{HCl}+\mathrm{H}_{3} \mathrm{PO}_{4}$ mixtures containing up to $60 \mathrm{~mol} \%$ of $\mathrm{H}_{2} \mathrm{SO}_{4}$ and $\mathrm{HCl}$, respectively. In the case of high-strength steels, the CIs not only slow down the general corrosion of the metal, but also considerably prevent its hydrogenation. The role of urotropine in the protective action of the mixture made it possible to understand the results of potentiometric studies of $\mathrm{H}_{2} \mathrm{SO}_{4}+\mathrm{H}_{3} \mathrm{PO}_{4}$ and $\mathrm{HCl}+\mathrm{H}_{3} \mathrm{PO}_{4}$ solutions containing $\mathrm{Fe}$ (III) salts. It was shown that urotropine present in them additionally binds $\mathrm{Fe}$ (III) cations into complex compounds, which further reduces the oxidizing capacity of the systems [121].

Thus, inhibited acid solutions that are resistant to the accumulation of Fe(III) salts can be created by combining the ability of acid solutions containing $\mathrm{H}_{3} \mathrm{PO}_{4}$ to bind $\mathrm{Fe}(\mathrm{III})$ cations into phosphate complexes that are less corrosive towards steels, and the unique properties of the IFKhAN-92 + KNCS + urotropine formulation. This formulation not only forms a 
protective polymolecular CI layer on the metal surface from IFKhAN-92 molecules, Fe(II) cations and thiocyanate anions that efficiently inhibits the reduction of $\mathrm{Fe}(\mathrm{III})$, but also, due to the presence of urotropine, additionally reduces the oxidizing ability of $\mathrm{Fe}$ (III) cations. Similar regularities are observed in the protection of low-carbon steel in weakly acid solutions of disodium ethylenediaminetetraacetate $\left(100^{\circ} \mathrm{C}\right)$ by mixed CIs (Table 11) [122]. If this corrosive environment contains ligands, i.e., anions of ethylenediaminetetraacetic acid capable of binding Fe(III) into strong complex compounds, and efficient CIs of steel based on pyridine derivatives, it becomes possible to slow down its corrosion significantly even in the presence of a $\mathrm{Fe}$ (III) salt in the system. The presence of $1 \mathrm{~g} / \mathrm{L} \mathrm{FeCl}{ }_{3}$ in a solution containing disodium ethylenediaminetetraacetate + composite $\mathrm{CI}$ accelerates steel corrosion, but the maximum observed $k$ value is as small as $2.28 \mathrm{~g} /\left(\mathrm{m}^{2} \cdot \mathrm{h}\right)$, which is 16.3 times lower than in the background environment.

Table 11. Corrosion rates $\left(k, \mathrm{~g} /\left(\mathrm{m}^{2} \cdot \mathrm{h}\right)\right)$ and corrosion inhibition coefficients $(\gamma)$ of steel 10 in $0.02 \mathrm{M}$ ethylenediaminetetraacetic acid disodium salt, containing $\mathrm{FeCl}_{3} . t=100^{\circ} \mathrm{C}$.

\begin{tabular}{|c|c|c|c|c|c|c|c|c|}
\hline \multirow{2}{*}{ Corrosion inhibitor } & \multicolumn{4}{|c|}{ Without $\mathrm{FeCl}_{3}$} & \multicolumn{4}{|c|}{$1 \mathrm{~g} / \mathrm{L} \mathrm{FeCl} 3$} \\
\hline & $\boldsymbol{k}$ & $\gamma$ & $\mathbf{p} \mathbf{H}_{0}^{*}$ & $\mathbf{p} \mathbf{H}_{\text {fin }}^{* *}$ & $\boldsymbol{k}$ & $\gamma$ & pHo & pHfin \\
\hline- & 16.60 & - & 4.40 & 7.05 & 37.20 & - & 3.70 & 6.80 \\
\hline $\begin{array}{c}0.1 \% \text { Catapine } \mathrm{A}+ \\
0.03 \% \text { thiourea }\end{array}$ & 0.27 & 61.4 & 4.40 & 4.45 & 1.98 & 18.7 & 3.70 & 3.85 \\
\hline $\begin{array}{c}0.1 \% \mathrm{I}-1-\mathrm{V}+0.03 \% \\
\text { thiourea }\end{array}$ & 0.22 & 75.5 & 4.40 & 4.43 & 2.28 & 16.3 & 3.70 & 3.90 \\
\hline $\begin{array}{c}0.05 \% \mathrm{I}-1-\mathrm{A}+0.03 \% \\
\text { thiourea }\end{array}$ & 0.28 & 59.5 & 4.40 & 4.45 & 2.03 & 18.3 & 3.70 & 3.85 \\
\hline $\begin{array}{c}0.1 \% \text { Catapine } \mathrm{A}+ \\
0.03 \% \text { captax }\end{array}$ & 0.25 & 66.5 & 4.40 & 4.45 & 1.79 & 20.1 & 3.70 & 3.80 \\
\hline
\end{tabular}

* Initial acidity of the solution. ** Final acidity of the solution.

\section{Conclusions}

The physicochemical parameters of acid solutions containing Fe(III) salts are largely determined by their anionic composition. Anions of acids can strongly bind Fe(III) cations into complex compounds, thereby reducing their oxidizing ability and mobility in solution. Binding Fe(III) cations into complex compounds by the components of an acid solution changes the thermodynamic and kinetic characteristics of such systems. This fact allows one to predict and control the properties of acid solutions containing Fe(III) salts. Addition of acids $\left(\mathrm{H}_{3} \mathrm{PO}_{4}\right.$ and $\left.\mathrm{HF}\right)$ that dissociate to generate anions capable of forming complexes with $\mathrm{Fe}(\mathrm{III})$ can significantly reduce the corrosivity of the solutions. $\mathrm{H}_{3} \mathrm{PO}_{4}$ is the most promising acid in this respect. In widely used $\mathrm{HCl}$ and $\mathrm{H}_{2} \mathrm{SO}_{4}$ solutions, accumulation of $\mathrm{Fe}$ (III) salts 
is undesirable, since it significantly increases their corrosivity due to the weak ability of these acids to form complexes with Fe(III) cations.

Cyclic voltammetry of inert electrodes (platinum, gold) is a versatile method for determining the oxidizing ability and mobility of Fe(III) cations in acid solutions. Data on the oxidizing ability of $\mathrm{Fe}$ (III) cations can be obtained from potentiometric studies of the $\mathrm{Fe}(\mathrm{III}) / \mathrm{Fe}$ (II) redox couple in acid solutions on a platinum electrode. The diffusion coefficients of $\mathrm{Fe}(\mathrm{III})$ cations in acid solutions are calculated on the basis of voltammetric measurements in these media on rotating electrodes (platinum, steel).

The corrosion of low-carbon steels in acid solutions containing Fe(III) is due to three partial reactions: anodic ionization of iron; cathodic reduction of protons and $\mathrm{Fe}$ (III) cations. The first two reactions occur under kinetic control, while the last one, under diffusion control. The presence of Fe(III) salts in acid solutions significantly accelerates corrosion, which is a consequence of the predominant acceleration of the cathodic reaction by Fe(III). The corrosion of steels in these environments is sensitive to the effect of the convective factor, which is typical of processes under diffusion control.

In acid solutions, steels, primarily alloyed ones, can be transferred by Fe(III) salts to a stable passive state that ensures their protection. However, this protection method is unreliable, since as $C_{\mathrm{Fe}(\mathrm{III})}$ in a corrosive medium or its flow velocity decrease, steel can pass to an unstable passive state or even return to corrosion in the region of its active dissolution.

The inhibitory protection of steels in solutions of various acids containing Fe(III), especially under dynamic conditions, is inefficient. This problem is solved by using solutions of mixtures of acids based on $\mathrm{H}_{3} \mathrm{PO}_{4}$ and additives of the mixed CI containing IFKhAN-92. In solutions of $\mathrm{H}_{2} \mathrm{SO}_{4}+\mathrm{H}_{3} \mathrm{PO}_{4}$ and $\mathrm{HCl}+\mathrm{H}_{3} \mathrm{PO}_{4}$ mixtures containing $60 \mathrm{~mol} \% \mathrm{H}_{2} \mathrm{SO}_{4}$ or $\mathrm{HCl}$, efficient protection of low-carbon and high-strength steels is achieved by the IFKhAN$92+$ KNCS + urotropine mixture (molar ratio of components: 9:1:400).

A study of these systems made it possible to formulate a scientific approach to the creation of inhibited acid solutions resistant to the accumulation of $\mathrm{Fe}$ (III). It is based on the ability of acid solutions containing $\mathrm{H}_{3} \mathrm{PO}_{4}$ to bind $\mathrm{Fe}(\mathrm{III})$ cations into phosphate complexes and the unique properties of the IFKhAN-92 + KNCS + urotropine formulation. This formulation not only forms a polymolecular protective CI layer on the metal surface from IFKhAN-92 molecules, Fe(II) cations and thiocyanate anions that efficiently inhibits Fe(III) reduction, but also, due to the presence of urotropine, additionally lowers the oxidizing ability of $\mathrm{Fe}(\mathrm{III})$ cations.

In steel etching or in acid washing of steel equipment leading to the accumulation of $\mathrm{Fe}(\mathrm{III})$ in acids, no more than $40 \% \mathrm{HCl}$ or $\mathrm{H}_{2} \mathrm{SO}_{4}$ should be replaced with phosphoric acid, and the IFKhAN-92 + KNCS + urotropine formulation should be used as a corrosion inhibitor. 


\section{References}

1. I.B. Obot, A. Meroufel, I.B. Onyeachu, A. Alenazi and A.A. Sorour, Corrosion inhibitors for acid cleaning of desalination heat exchangers: Progress, challenges and future perspectives, J. Mol. Liq., 2019, 296, 111760. doi: 10.1016/j.molliq.2019.111760

2. C. Verma, M.A. Quraishi and E.E. Ebenso, Corrosive electrolytes, Int. J. Corros. Scale Inhib., 2020, 9, no. 4, 1261-1276. doi: 10.17675/2305-6894-2020-9-4-5

3. L.V. Hong and H.B. Mahmud, A preliminary screening and characterization of suitable acids for sandstone matrix acidizing technique: a comprehensive review, J. Pet. Explor. Prod. Technol., 2019, 9, 753-778. doi: 10.1007/s13202-018-0496-6

4. L.V. Hong and H.B. Mahmud, A Comparative Study of Different Acids used for Sandstone Acid Stimulation: A Literature Review, IOP Conf. Ser.: Mater. Sci. Eng., 2017, 217, 012018. doi: 10.1088/1757-899X/217/1/012018

5. M.U. Shafiq and H.B. Mahmud, Sandstone matrix acidizing knowledge and future development, J. Pet. Explor. Prod. Technol., 2017, 7, no. 4, 1205-1216. doi: 10.1007/s13202-017-0314-6

6. B. Guo, X. Liu and X. Tan, Chapter 13. Acidizing, in Petroleum Production Engineering, Gulf Professional Publishing, 2nd Edition, 2017, 367-387. doi: 10.1016/B978-0-12-809374-0.00013-1

7. A. Agrawal and K.K. Sahu, An overview of the recovery of acid from spent acidic solutions from steel and electroplating industries, J. Hazard. Mater., 2009, 171, 61-75. doi: 10.1016/j.jhazmat.2009.06.099

8. F. Rögener, Yu.A. Lednova, M.Yu. Andrianova and A.V. Lednov, Sustainable stainless steel - A review on acid regeneration systems for application in continuous etching lines, Vestnik Magnitogorskogo gosudarstvennogo tekhnicheskogo universiteta im. G.I. Nosova (Vestnik of Nosov Magnitogorsk State Technical University), 2019, 17, no. 2, 38-48. doi: 10.18503/1995-2732-2019-17-2-38-48

9. J.A. Richardson and Md Sayem H.Bhuiyan, Corrosion in Hydrogen Halides and Hydrohalic Acids, Reference Module in Materials Science and Materials Engineering, Elsevier Inc., 2017, 1-22. doi: 10.1016/B978-0-12-803581-8.10372-8

10. Z. Panossian, N.L. de Almeida, R.M.F. de Sousa, G. de Souza Pimenta and L.B.S. Marques, Corrosion of carbon steel pipes and tanks by concentrated sulfuric acid: A review, Corros. Sci., 2012, 58, 1-11. doi: 10.1016/j.corsci.2012.01.025

11. R.Y. Chen and W.Y.D. Yuen, A Study of the Scale Structure of Hot-Rolled Steel Strip by Simulated Coiling and Cooling, Oxid. Met., 2000, 53, no. 5/6, 539-560. doi: 10.1023/A:1004637127231

12. R.Y. Chen and W.Y.D. Yuen, Oxide-Scale Structures Formed on Commercial HotRolled Steel Strip and Their Formation Mechanisms, Oxid. Met., 2001, 56, no. 1/2, 89118. doi: $\underline{10.1023 / A: 1010395419981}$ 
13. R.Y. Chen and W.Y.D. Yuen, Oxidation of Low-Carbon, Low-Silicon Mild Steel at 450-900 ${ }^{\circ} \mathrm{C}$ Under Conditions Relevant to Hot-Strip Processing, Oxid. Met., 2002, 57, no. 1/2, 53-79. doi: 10.1023/A:1013390628475

14. R.Y. Chen and W.Y.D. Yuen, Review of the High-Temperature Oxidation of Iron and Carbon Steels in Air or Oxygen, Oxid. Met., 2003, 59, no. 5/6, 433-468. doi: 10.1023/A:1023685905159

15. P.H. Bolt, Understanding the Properties of Oxide Scales on Hot Rolled Steel Strip, Steel Res. Int., 2004, 75, no. 6, 399-404. doi: 10.1002/srin.200405786

16. S.L.J. de Oliveira, J.C. Bellon, P.A.J. de Souza, F.G.A. da Silva and A.B. Cota, Effect of Processing Parameters on Scale Formation During Hot Steel Strip Rolling, Mater. Res., 2010, 13, no. 1, 11-14. doi: 10.1590/S1516-14392010000100004

17. R. Endo, T. Yagi, M. Ueda and M. Susa, Thermal Diffusivity Measurement of Oxide Scale Formed on Steel during Hot-rolling Process, ISIJ Int., 2014, 54, no. 9, 2084-2088. doi: $10.2355 /$ isijinternational.54.2084

18. T. Kizu, Y. Nagataki, T. Inazumi and Y. Hosoya, Effects of Chemical Composition and Oxidation Temperature on the Adhesion of Scale in Plain Carbon Steels, ISIJ Int., 2001, 41, no. 12, 1494-1501. doi: 10.2355/isijinternational.41.1494

19. N. Yukawa, E. Abe and S. Fujiwara, Thermal properties of oxide scale on surface of work roll in hot rolling mill, Procedia Manuf., 2018, 15, 59-64. doi: 10.1016/j.promfg.2018.07.170

20. S. Yamaguchi, T. Yoshida and T. Saito, Improvement in Descaling of Hot Strip by Hydrochloric Acid, ISIJ Int., 1994, 34, no. 8, 670-678. doi: 10.2355/isijinternational.34.670

21. Y. Jatuphaksamphan, N. Phinichka, K. Prapakorn and M. Supradist, Pickling kinetics of tertiary oxide scale formed on hot-rolled steel strip, J. Met., Mater. Miner., 2010, 20, no. $1,33-39$.

22. S. Chandra-Ambhorn, T. Somphakdee and W. Chandra-Ambhorn, Characterisation and Pickling Behaviour of Thermal Oxide Scale on Low Carbon Steel Produced from a Thin Slab, Mater. Sci. Forum, 2011, 696, 156-161. doi: 10.4028/www.scientific.net/MSF.696.156

23. M.J.L. Gines, G.J. Benitez, T. Perez, E. Merli, M.A. Firpo and W. EgliI, Study of the picklability of $1.8 \mathrm{~mm}$ hot-rolled steel strip in hydrochloric acid, Lat. Am. Appl. Res., 2002, 32, 281-288.

24. Ya.G. Avdeev, I.G. Gorichev and A.Yu. Luchkin, Effect of IFKhAN-92 inhibitor on scale removal during sulfuric acid etching of steel, Int. J. Corros. Scale Inhib., 2012, 1, no. 1, 26-37. doi: $\underline{10.17675 / 2305-6894-2012-1-1-026-037}$ 
25. A.Yu. Luchkin, Fiziko-khimicheskie aspekty zashchity stali ot kislotnoi korrozii proizvodnymi triazola pri povyshennykh temperaturakh (Physicochemical aspects of steel protection against acid corrosion by triazole derivatives at elevated temperatures), Dissertatsiya kandidata khimicheskikh nauk (PhD Chemistry Dissertation), Moscow State Pedagogical University, A.N. Frumkin Institute of Physical Chemistry and Electrochemistry, RAS, Moscow, 2013, 127 pp. (in Russian).

26. A.E. Chastukhin, A.D. Izotov, I.G. Gorichev and A.M. Kutepov, Analysis of $\mathrm{Fe}_{2} \mathrm{O}_{3}$ and $\mathrm{Fe}_{3} \mathrm{O}_{4}$ Dissolution Kinetics in Terms of the Chain Mechanism Model, Theor. Found. Chem. Eng., 2003, 37, 398-406. doi: 10.1023/A:1025084705089

27. A.V. Kuzin, I.G. Gorichev and Yu.A. Lainer, Stimulating Effect of Phosphate Ions on the Dissolution Kinetics of Iron Oxides in an Acidic Medium, Russ. Metall. (Metally), 2013, no. 9, 652-657. doi: 10.1134/S0036029513090073

28. J.C. Hemmelmann, H. Xu and W. Krumm, Empirical Modeling of Iron Oxide Dissolution in Sulphuric and Hydrochloric Acid, Metall. Mater. Trans. B, 2013, 44, 1232-1235. doi: 10.1007/s11663-013-9893-X

29. A.V. Kuzin, I.G. Gorichev, E.A. Eliseeva and L.E. Slynko, The Effect of Stoichiometry of Iron(II) and (III) and Magnetite Oxides on the Kinetic Regularities of their Dissolution in Orthophosphoric Acid Containing Fe(II) and Fe(III) Ions, Vestn. MGTU N. E. Baumana, Ser. Estestv. Nauki, 2019, no. 2, 104-113. doi: 10.18698/1812-3368-2019-2104-113

30. R. Salmimies, M. Mannila, J. Kallas and A. Häkkinen, Acidic dissolution of magnetite: experimental study on the effects of acid concentration and temperature, Clays Clay Miner., 2011, 59, 136-146. doi: 10.1346/CCMN.2011.0590203

31. R. Salmimies, M. Mannila, J. Kallas and A. Häkkinen, Acidic dissolution of hematite: kinetic and thermodynamic investigations with oxalic acid, Int. J. Miner. Process., 2012, 110-111, 121-125. doi: 10.1016/j.minpro.2012.04.001

32. R. Salmimies, P. Vehmaanperä and A. Häkkinen, Acidic dissolution of magnetite in mixtures of oxalic and sulfuric acid, Hydrometallurgy, 2016, 163, 91-98. doi: 10.1016/j.hydromet.2016.03.011

33. P. Vehmaanperä, R. Salmimies and A. Häkkinen, Thermodynamic and Kinetic Studies of Dissolution of Hematite in Mixtures of Oxalic and Sulfuric Acid, Min., Metall., Explor., 2021, 38, 69-80. doi: 10.1007/s42461-020-00308-4

34. F.J. Garcia, A. Rubio, E. Sainz, P. Gonzalez and F.A. Lopez, Preliminary study of treatment of sulphuric etching water waste from steelmaking by bio-oxidation with Thiobacillus ferrooxidans, FEMS Microbiol. Rev., 1994, 14, no. 4, 397-404. doi: 10.1111/j.1574-6976.1994.tb00114.x

35. H. Brunckova and S. Niznik, Influence of Iron in Etching Solution of Sulfuric Acid on its Activity, Chem. Papers, 1992, 46, no. 3, 170-173.

36. A. Chekioua and R. Delimi, Purification of $\mathrm{H}_{2} \mathrm{SO}_{4}$ of etching bath contaminated by $\mathrm{Fe}(\mathrm{II})$ ions using electrodialysis process, Energy Procedia, 2015, 74, 1418-1433. doi: 10.1016/j.egypro.2015.07.789 
37. J. Zhai, C. Jiang and J. Wu, Waste Steel-etching Sulphuric Acid Removal Treated by Freezing Crystallization-Acid Retardation Coupling Technology, Adv. Mater. Res., 2014, 955-959, 2915-2918. doi: 10.4028/www.scientific.net/AMR.955-959.2915

38. V.N. Glushchenko and M.A. Silin, Neftepromyslovaya khimiya. Vol. 4. Kislotnaya obrabotka skvazyn (Oilfield chemistry. Vol. 4. Matrix acidizing), Ed.: I.T. Mishchenko, Intercontact Nauka, Moscow, 2010, 703 p. (in Russian).

39. Ya.G. Avdeev, A.V. Panova, T.E. Andreeva and Yu.I. Kuznetsov, Vliyanie solei Fe(III) na zashchitu stalei v rastvorakh mineral'nykh kislot ingibitorami korrozii (The effect of $\mathrm{Fe}$ (III) salts on the protection of steels in solutions of mineral acids by corrosion inhibitors), Korroz.: Mater., Zashch. (Corrosion: Materials, Protection), 2019, no. 11, 32-40 (in Russian). doi: 10.31044/1813-7016-2019-0-11-32-40

40. M.M. Rakhimova, T.M. Nurmatov, N.Z. Yusupov, M.A. Ismailova and E. Faizullaev, Iron Complexes with Monocarboxylate Anions: Models of Their Formation, Russ. J. Inorg. Chem., 2013, 58, no. 6, 719-723. doi: 10.1134/S003602361306020X

41. M.M. Rakhimova, N.Z. Yusupov, K.Dzh. Suyarov, K.G. Khasanova and Sh. Bekbudova, Iron Succinate Coordination Compounds. Simulation of Formation Processes, Russ. J. Inorg. Chem., 2013, 58, no. 8, 972-975. doi: 10.1134/S0036023613080196

42. M.M. Rakhimova, Kompleksoobrazovanie ionov $\mathrm{Fe}, \mathrm{Co}, \mathrm{Mn} i \mathrm{Cu}$ s odno- $i$ mnogoosnovnymi organicheskimi kislotami, neitral'nymi ligandami $v$ vodnykh rastvorakh. Avtoreferat dissertatsii doktora khimicheskih nauk. (Complexation of Fe, $\mathrm{Co}, \mathrm{Mn}$, and Cu ions with mono- and polybasic organic acids, neutral ligands in aqueous solutions. Abstract of the Doctor of science dissertation), Tadzhikskii natsional'nyi universitet, Dushanbe, 2013, 34 pp. (in Russian).

43. J.-Y. Lee, J.Y. Oh, K.Y. Putri, M.H. Baik and J.-I. Yun, Redox behaviors of Fe(II/III) and U(IV/VI) studied in synthetic water and KURT groundwater by potentiometry and spectroscopy, J. Radioanal. Nucl. Chem., 2017, 312, 221-231. doi: 10.1007/s10967$\underline{017-5233-\mathrm{y}}$

44. I. Guzman, S.J. Thorpe and V.G. Papangelakis, Redox potential measurements in the $\mathrm{H}_{2} \mathrm{SO}_{4}-\mathrm{FeSO}_{4}-\mathrm{Fe}_{2}\left(\mathrm{SO}_{4}\right)_{3}-\mathrm{H}_{2} \mathrm{O}$ system at high temperature using an Ir electrode, $J$. Electroanal. Chem., 2017, 799, 399-405. doi: 10.1016/j.jelechem.2017.06.036

45. Ya.G. Avdeev, T.E. Andreeva and Yu.I. Kuznetsov, A potentiometric study of an $\mathrm{H}_{2} \mathrm{SO}_{4}-\mathrm{H}_{3} \mathrm{PO}_{4}-\mathrm{H}_{2} \mathrm{O}$ system containing $\mathrm{Fe}(\mathrm{III})$ and $\mathrm{Fe}(\mathrm{II})$ cations, Int. J. Corros. Scale Inhib., 2018, 7, no. 3, 366-375. doi: 10.17675/2305-6894-2018-7-3-7

46. Ya.G. Avdeev, T.E. Andreeva, A.V. Panova and Yu.I. Kuznetsov, Effect of anionic composition of solutions of mineral acids containing Fe(III) on their oxidizing properties, Int. J. Corros. Scale Inhib., 2019, 8, no. 1, 139-149. doi: $10.17675 / 2305-$ 6894-2019-8-1-12

47. L.N. Filatova, A.G. Vendilo and R.A. Sandu, Chemical forms of iron(III) in solutions of orthophosphoric acid as probed by electronic absorption spectroscopy, Russ. J. Inorg. Chem., 2012, 57, no. 9, 1272-1275. doi: 10.1134/S0036023612090057 
48. F. Al-Sogair, H.M. Marafie, N.M. Shuaib, H.B. Youngo and M.S. El-Ezaby, Interaction of Phosphate with Iron(III) in Acidic Medium, Equilibrium and Kinetic Studies, $J$. Coord. Chem., 2002, 55, no. 9, 1097-1109. doi: 10.1080/0095897021000010053

49. G. Lente, M.E.A. Magalhaes and I. Fabian, Kinetics and Mechanism of Complex Formation Reactions in the Iron(III)-Phosphate Ion System at Large Iron(III) Excess. Formation of a Tetranuclear Complex, Inorg. Chem., 2000, 39, no. 9,1950-1954. doi: 10.1021/ic991017p

50. H.M.N. Akhtar, A.A. Shaikh and M.Q. Ehsan, Cyclic Voltammetric Study of the Redox Behavior of $\mathrm{Fe}(\mathrm{II}) / \mathrm{Fe}$ (III) Systems Forming During the Oxidation of $\mathrm{Fe}(\mathrm{II})$ Complexes with Saccharin and with Saccharin and 1,10-Phenanthroline, Russ. J. Electrochem., 2008, 44, no. 12, 1403-1408. doi: 10.1134/S102319350812015X

51. M.H. Bridge, E. Williams, M.E.G. Lyons, K.F. Tipton and W. Linert, Electrochemical investigation into the redox activity of $\mathrm{Fe}(\mathrm{II}) / \mathrm{Fe}(\mathrm{III})$ in the presence of nicotine and possible relations to neurodegenerative diseases, Biochim. Biophys. Acta, 2004, 1690, 77-84. doi: $10.1016 /$ j.bbadis.2004.05.007

52. J. Vatrál, R. Boca and W. Linert, Electrochemical investigation of the redox couple $\mathrm{Fe}(\mathrm{III}) / \mathrm{Fe}$ (II) in the presence of amino acids and neurotransmitters, Electrochim. Acta, 2014, 145, 53-63. doi: 10.1016/j.electacta.2014.08.079

53. M.M. Radhi, E.A. Jaffar Al-Mulla and W.T. Tan, Electrochemical haracterization of the redox couple of $\mathrm{Fe}(\mathrm{III}) / \mathrm{Fe}$ (II) mediated by grafted polymer electrode, Res. Chem. Intermed., 2012, 38, no. 9, 179-192. doi: 10.1007/s11164-012-0954-6

54. Q. Xu, T.S. Zhao, L. Wei, C. Zhang and X.L. Zhou, Electrochemical characteristics and transport properties of $\mathrm{Fe}(\mathrm{II}) / \mathrm{Fe}(\mathrm{III})$ redox couple in a non-aqueous reline deep eutectic solvent, Electrochim. Acta, 2015, 154, 462-467. doi: 10.1016/j.electacta.2014.12.061

55. Y.H. Wen, H.M. Zhang, P. Qian, H.T. Zhou, P. Zhao, B.L. Yi and Y.S. Yang, Studies on Iron $\left(\mathrm{Fe}^{3+} / \mathrm{Fe}^{2+}\right)-$ Complex/Bromine $\left(\mathrm{Br}_{2} / \mathrm{Br}^{-}\right)$Redox Flow Cell in Sodium Acetate Solution, J. Electrochem. Soc., 2006, 153, no. 5, A929-A934. doi: 10.1149/1.2186040

56. S.K. Guin, R. Chandra and S.K. Aggarwal, Influence of ionic speciation on electrocatalytic performance of polyaniline coated platinum electrode: $\mathrm{Fe}(\mathrm{III}) / \mathrm{Fe}(\mathrm{II})$ redox reaction, Electrochim. Acta, 2010, 55, 8402-8409. doi: 10.1016/j.electacta.2010.07.052

57. D. Lloyd, T. Vainikka, M. Ronkainen and K. Kontturi, Characterisation and application of the $\mathrm{Fe}(\mathrm{II}) / \mathrm{Fe}(\mathrm{III})$ redox reaction in an ionic liquid analogue, Electrochim. Acta, 2013, 109, 843-851. doi: $10.1016 /$ j.electacta.2013.08.013

58. S. Mohr and T. Bechtold, Electrochemical behaviour of iron-complexes in presence of competitive ligands: A strategy for optimization of current density, J. Appl. Electrochem., 2001, 31, 363-368. doi: 10.1023/A:1017536204530

59. J. Pelle, N. Gruet, B. Gwinner, M.L. Schlegel and V. Vivier, On the role of Fe(III) ions on the reduction mechanisms of concentrated nitric acid, Electrochim. Acta, 2020, 335, 135578. doi: $10.1016 /$ j.electacta.2019.135578 
60. B. Belqat, A. Laghzizil, K. Elkacimi, A. Bouhaouss and S. Belcadi, Fluoride effect on the electrochemical behaviour of the $\mathrm{Fe}(\mathrm{III}) / \mathrm{Fe}(\mathrm{II})$ system in $\mathrm{H}_{3} \mathrm{PO}_{4}+\mathrm{H}_{2} \mathrm{O}+\mathrm{HF}, J$. Fluorine Chem., 2000, 105, 1-5. doi: 10.1016/S0022-1139(00)00256-6

61. Ya.G. Avdeev, T.E. Andreeva, A.V. Panova and E.N. Yurasova, A study of the $\mathrm{H}_{2} \mathrm{SO}_{4}-$ $\mathrm{H}_{3} \mathrm{PO}_{4}-\mathrm{H}_{2} \mathrm{O}-\mathrm{Fe}(\mathrm{III})$ system by cyclic voltammetry, Int. J. Corros. Scale Inhib., 2019, 8 , no. 2, 411-421. doi: 10.17675/2305-6894-2019-8-2-18

62. Ya.G. Avdeev, T.E. Andreeva, A.V. Panova and Yu.I. Kuznetsov, Cyclic voltammetric study of the $\mathrm{HCl}-\mathrm{H}_{3} \mathrm{PO}_{4}-\mathrm{H}_{2} \mathrm{O}-\mathrm{Fe}(\mathrm{III})$ system, Int. J. Corros. Scale Inhib., 2020, 9, no. 2, 538-549. doi: 10.17675/2305-6894-2020-9-2-9

63. A.F. Gil, L. Galicia and I. González, Diffusion coefficients and electrode kinetic parameters of different Fe(III)-sulfate complexes, J. Electroanal. Chem., 1996, 417, no. 1-2, 129-134. doi: 10.1016/S0022-0728(96)04735-3

64. M.D. Benari and G.T. Hefter, The corrosion of silver, copper, palladium and gold by $\mathrm{Fe}(\mathrm{III})$ and $\mathrm{Cu}(\mathrm{II})$ in dimethylsulphoxide and water solutions, Electrochim. Acta, 1991, 36, no. 3-4, 479-488. doi: 10.1016/0013-4686(91)85131-P

65. Z.-C. Wu, Y. Awakura, S. Ando and H. Majima, Determination of the Diffusion Coefficients of $\mathrm{CuCl}_{2}, \mathrm{FeCl}_{3}, \mathrm{CuSO}_{4}$, and $\mathrm{Fe}_{2}\left(\mathrm{SO}_{4}\right)_{3}$ in Aqueous Solutions, Mater. Trans., JIM, 1990, 31, no. 12, 1065-1071. doi: 10.2320/matertrans1989.31.1065

66. F. Dalton, ECS Classics: Historical Origins of the Rotating Ring-Disk Electrode, Electrochem. Soc. Interface, 2016, 25, 50-59. doi: 10.1149/2.F03163if

67. F.C. Walsh, A.H. Nahlé, J.A. Wharton and L.F. Arenas, The rotating cylinder electrode for studies of corrosion engineering and protection of metals - An illustrated review, Corros. Sci., 2017, 123, 1-20. doi: 10.1016/j.corsci.2017.03.024

68. C. Du, Q. Tan, G. Yin and J. Zhang, Rotating Disk Electrode Method, in Rotating Electrode Methods and Oxygen Reduction Electrocatalysts, 2014, 171-198. doi: 10.1016/B978-0-444-63278-4.00005-7

69. Z. Jia, G. Yin and J. Zhang, Rotating Ring-Disk Electrode Method, in Rotating Electrode Methods and Oxygen Reduction Electrocatalysts, 2014, 199-229. doi: 10.1016/B978-0-444-63278-4.00006-9

70. S.A. Balezin, N.I. Podobaev and V.A. Karpov, Pribor s diskovym vrashchayushchimsya obraztsom dlya korrozionnykh ispytanii (Device with a disk rotating sample for corrosion testing), in Ingibitory korrozii metallov. (Metal Corrosion Inhibitors.), Eds.: S.A. Balezin, F.B. Glilina, N.I. Podobaev, N.G. Klyuchnikov and E.G. Zak, MGPI im V.I. Lenina, Moscow, 1969, 85-91 (in Russian).

71. V.A. Karpov and A.K. Akhlebinin, O rastvorenii stalei v rastvorakh khlorida zheleza(III) (On the dissolution of steels in iron(III) chloride solutions), in Ingibitory korrozii metallov (Metal Corrosion Inhibitors), Ed.: S.A. Balezin, MGPI im. V.I. Lenina, Moscow, 1979, 44-47 (in Russian).

72. Ya.G. Avdeev and Yu.I. Kuznetsov, Inhibitory protection of steels from hightemperature corrosion in acid solutions. A review. Part 1., Int. J. Corros. Scale Inhib., 2020, 9, no. 2, 394-426. doi: 10.17675/2305-6894-2020-9-2-2 
73. V.A. Karpov and A.K. Akhlebinin, O mekhanizme rastvoreniya stalei v rastvorakh khlorida zheleza(III) (On the mechanism of steel dissolution in iron(III) chloride solutions), in Ingibitory korrozii metallov (Metal Corrosion Inhibitors), Ed.: S.A. Balezin, MGPI im V.I. Lenina, Moscow, 1980, 10-15 (in Russian).

74. Yu.V. Balaban-Irmenin and L.A. Litvinova, O vliyanii ionov trekhvalentnogo zheleza na protsess korrozii stalei v kislykh sredakh (On the effect of ferric ions on the corrosion process of steels in acidic media), Zashch. Met. (Protection of metals), 1978, 14, no. 4, 475-477 (in Russian).

75. Ya.G. Avdeev and T.E. Andreeva, Characteristics of the Mechanism of Corrosion of Low-Carbon Steels in Acid Solutions Containing Fe(III) Salts, Russ. J. Phys. Chem. A, 2021, 95, no. 6, 1128-1136. doi: 10.1134/S0036024421060029

76. H. Kaesche, Corrosion of metals. Physicochemical principles and current problems, Metallurgiya, Moscow, 1984, 400 pp. (translation into Russian).

77. J. Peng and M. Li, Etching Behaviour of 2205 Duplex Stainless Steel Hot-Rolled Strips in Sulfuric Acid Electrolytes, Adv. Mater. Sci. Eng., 2020, 4562418, 10 pp. doi: 10.1155/2020/4562418

78. L.-F. Li, P. Caenen and J.-P. Celis, Effect of hydrochloric acid on etching of hot-rolled 304 stainless steel in iron chloride-based electrolytes, Corros. Sci., 2008, 50, 804-810. doi: $10.1016 /$ j.corsci.2007.09.006

79. K. Xiao, Z. Li, J. Song, Z. Bai, W. Xue, J. Wu and C. Dong, Effect of Concentrations of $\mathrm{Fe}^{2+}$ and $\mathrm{Fe}^{3+}$ on the Corrosion Behavior of Carbon Steel in $\mathrm{Cl}^{-}$and $\mathrm{SO}_{4}^{2-}$ Aqueous Environments, Met. Mater. Int., 2021, 27, 2623-2633. doi: 10.1007/s12540-019-00590-y

80. I. Saefuloh, N. Kanani, F.G. Ramadhan, Y. Rukmayadi, Y. Yusuf, S. Abdullah and S. Susilo, The Study of Corrosion Behavior and Hardness of AISI Stainless Steel 304 in Concentration of Chloride Acid Solution and Temperature Variations, J. Phys.: Conf. Ser., 2020, 1477, 052058. doi: 10.1088/1742-6596/1477/5/052058

81. Ya.G. Avdeev, O.A. Kireeva, Yu.I. Kuznetsov and I.G. Gorichev, Effect of the anionic composition of acidic solutions containing Fe(III) on the protection of low-carbon steel by a triazole inhibitor, Int. J. Corros. Scale Inhib., 2016, 5, no. 4, 333-346. doi: 10.17675/2305-6894-2016-5-4-4

82. Ya.G. Avdeev, L.V. Frolova, A.V. Panova, K.L. Anfilov and Yu.I. Kuznetsov, Corrosion and hydrogenation of steels in solutions of mineral acids containing iron(III) salts, Int. J. Corros. Scale Inhib., 2020, 9, no. 1, 320-333. doi: 10.17675/2305-68942020-9-1-21

83. Ya.G. Avdeev, L.V. Frolova, A.V. Panova, K.L. Anfilov and Yu.I. Kuznetsov, Inhibitory protection of steels in hydrochloric and phosphoric acid mixtures containing Fe(III) salts, Int. J. Corros. Scale Inhib., 2020, 9, no. 3, 1084-1096. doi: 10.17675/23056894-2020-9-3-19

84. C. Bryce and D. Berk, Kinetics of the dissolution of copper in iron(III) chloride solutions, Ind. Eng. Chem. Res., 1995, 34, no. 4, 1412-1418. doi: 10.1021/ie00043a049 
85. Ya.G. Avdeev, Protection of metals in phosphoric acid solutions by corrosion inhibitors. A review, Int. J. Corros. Scale Inhib., 2019, 8, no. 4, 760-798. doi: 10.17675/23056894-2019-8-4-1

86. H.J. Won, N.O. Chang, S.Y. Park and S.B. Kim, Reductive Dissolution of Spinel-Type Iron Oxide by $\mathrm{N}_{2} \mathrm{H}_{4}-\mathrm{Cu}(\mathrm{I})-\mathrm{HNO}_{3}$, J. Korean Ceram. Soc., 2019, 56, no. 4, 387-393. doi: 10.4191/kcers.2019.56.4.04

87. K.R. Ansari, D.S. Chauhan, A. Singh, V.S. Saji and M.A. Quraishi, Corrosion Inhibitors for Acidizing Process in Oil and Gas Sectors, in Corrosion Inhibitors in the Oil and Gas Industry, Eds.: V.S. Saji and S.A. Umoren, Wiley-VCH Verlag GmbH \& Co. KGaA, Weinheim, Germany, 2020, 153-176. doi: 10.1002/9783527822140.ch6

88. M.A. Quraishi, D.S. Chauhan and V.S. Saji, Heterocyclic corrosion inhibitors for acid environments, in Heterocyclic Organic Corrosion Inhibitors, Eds.: M.A. Quraishi, D.S. Chauhan and V.S. Saji, Elsevier Inc., 2020, 87-131. doi: 10.1016/B978-0-12818558-2.00004-7

89. Ya.G. Avdeev and Yu.I. Kuznetsov, Physicochemical aspects of inhibition of acid corrosion of metals by unsaturated organic compounds, Russ. Chem. Rev., 2012, 81, no. 12, 1133-1145. doi: 10.1070/RC2012v081n12ABEH004292

90. Ya.G. Avdeev and Yu.I. Kuznetsov, Inhibitory protection of steels from hightemperature corrosion in acid solutions. A review. Part 2., Int. J. Corros. Scale Inhib., 2020, 9, no. 3, 867-902. doi: 10.17675/2305-6894-2020-9-3-5

91. Ya.G. Avdeev and Yu.I. Kuznetsov, Inhibitory protection of steels in acid solutions under high-temperature corrosion conditions. A review. Part 3, Int. J. Corros. Scale Inhib., 2020, 9, no. 4, 1194-1236. doi: 10.17675/2305-6894-2020-9-4-3

92. Ya.G. Avdeev, Protection of Steel in Solutions of Mineral Acids Using $\alpha, \beta$-Unsaturated Aldehydes, Ketones, and Azomethines, Prot. Met. Phys. Chem. Surf., 2015, 51, no. 7 , 1140-1148. doi: 10.1134/S2070205115070023

93. K. Rasheeda, Vijaya D.P. Alva, P.A. Krishnaprasad and S. Samshuddin, Pyrimidine derivatives as potential corrosion inhibitors for steel in acid medium - An overview, Int. J. Corros. Scale Inhib., 2018, 7, no. 1, 48-61. doi: 10.17675/2305-6894-2018-7-1-5

94. S.A. Umoren and M.M. Solomon, Effect of halide ions on the corrosion inhibition efficiency of different organic species - A review, J. Ind. Eng. Chem., 2015, 21, 81100. doi: $10.1016 /$ j.jiec.2014.09.033

95. M. Goyal, S. Kumar, I. Bahadur, C. Verma and E.E. Ebenso, Organic corrosion inhibitors for industrial cleaning of ferrous and nonferrous metals in acidic solutions: A review, J. Mol. Liq., 2018, 256, 565-573. doi: 10.1016/j.molliq.2018.02.045

96. T.J. Harvey, F.C. Walsh and A.H. Nahlé, A review of inhibitors for the corrosion of transition metals in aqueous acids, J. Mol. Liq., 2018, 266, 160-175. doi: 10.1016/j.molliq.2018.06.014

97. G. Gece, Drugs: A review of promising novel corrosion inhibitors, Corros. Sci., 2011, 53, 3873-3898. doi: 10.1016/j.corsci.2011.08.006 
98. A.A. Khadom and S.N. Farhan, Corrosion inhibition of steel in phosphoric acid, Corros. Rev., 2018, 36, no. 3, 267-280. doi: 10.1515/corrrev-2017-0104

99. Ch. Verma, D.K. Verma, E.E. Ebenso and M.A. Quraishi, Sulfur and phosphorus heteroatom-containing compounds as corrosion inhibitors: An overview, Heteroat. Chem., 2018, 29, no. 4, 20. doi: 10.1002/hc.21437

100. A. Singh and M.A. Quraishi, Acidizing Corrosion Inhibitors: A Review, J. Mater. Environ. Sci., 2015, 6, no. 1, 224-235.

101. M. Finšgar and J. Jackson, Application of corrosion inhibitors for steels in acidic media for the oil and gas industry: A review, Corros. Sci., 2014, 86, 17-41. doi: 10.1016/j.corsci.2014.04.044

102. C. Verma, E.E. Ebenso, M.A. Quraishi and C.M. Hussain, Recent developments in sustainable corrosion inhibitors: design, performance and industrial scale applications, Mater. Adv., 2021, 2, 3806-3850. doi: 10.1039/d0ma00681e

103. S.H. Zaferani, M. Sharifi, D. Zaarei and M.S. Reza, Application of eco-friendly products as corrosion inhibitors for metals in acid etching processes - A review, J. Environ. Chem. Eng., 2013, 1, 652-657. doi: 10.1016/j.jece.2013.09.019

104. C. Verma, E.E. Ebenso and M.A. Quraish, Ionic liquids as green and sustainable corrosion inhibitors for metals and alloys: An overview, J. Mol. Liq., 2017, 233, $403-$ 414. doi: $10.1016 /$ j.molliq.2017.02.111

105. A. Singh, E.E. Ebenso and M.A. Quraishi, Corrosion Inhibition of Carbon Steel in $\mathrm{HCl}$ Solution by Some Plant Extracts, Int. J. Corros., 2012, 897430, 20 p. doi: $\underline{10.1155 / 2012 / 897430}$

106. S. Bilgiç, Plant Extracts as Corrosion Inhibitors for Mild Steel in HCl Media - Review I, Int. J. Corros. Scale Inhib., 2021, 10, no. 1, 145-175. doi: 10.17675/2305-6894-2021$\underline{10-1-9}$

107. N.R. Devi, N. Karthiga, R. Keerthana, T. Umasankareswari, A. Krishnaveni, G. Singh and S. Rajendran, Extracts of leaves as corrosion inhibitors - An overview and corrosion inhibition by an aqueous extract of henna leaves (Lawsonia inermis), Int. J. Corros. Scale Inhib., 2020, 9, no. 4, 1169-1193. doi: 10.17675/2305-6894-2020-9-4-2

108. Ya.G. Avdeev and Yu.I. Kuznetsov, Nitrogen-containing five-membered heterocyclic compounds as corrosion inhibitors for metals in solutions of mineral acids - An overview, Int. J. Corros. Scale Inhib., 2021, 10, no. 2, 480-540. doi: 10.17675/23056894-2020-10-2-2

109. Yu.I. Kuznetsov, N.N. Andreev and A.I. Marshakov, Physicochemical Aspects of Metal Corrosion Inhibition, Russ. J. Phys. Chem., 2020, 94, no. 3, 505-515. doi: $\underline{10.1134 / \mathrm{S} 0036024420030152}$ 
110. S.A. Balezin, V.A. Karpov and N.I. Podobayev, Vliyanie ingibitorov na kinetiku rastvoreniya zheleza «Armko» v solyanoi kislote v prisutstvii nekotorykh okislitelei (Effect of inhibitors on the kinetics of Armco iron dissolution in hydrochloric acid in the presence of certain oxidants), in Ingibitory korrozii metallov (Metal Corrosion Inhibitors), Eds.: S.A. Balezin, F.B. Glilina, N.I. Podobaev, N.G. Klyuchnikov and E.G. Zak, Moscow, MGPI im. V.I. Lenina, 1969, 91-101 (in Russian).

111. F.B. Glilina, E.S. Bulavina and N.I. Podobayev, Zashchita ot korrozii stali marok St. 1 i EI $531 \mathrm{v}$ razbavlennykh rastvorakh solyanoi kisloty $\mathrm{v}$ prisutstvii khlorida zheleza (Corrosion protection of St. 1 and EI 531 grade steels in dilute solutions of hydrochloric acid in the presence of ferric chloride), in Ingibitory korrozii metallov (Metal Corrosion Inhibitors), Eds.: S.A. Balezin, F.B. Glilina, N.I. Podobaev, N.G. Klyuchnikov and E.G. Zak, Moscow, MGPI im. V.I. Lenina, 1969, 190-195 (in Russian).

112. N.I. Shadrina and F.B. Glilina, Ingibirovanie reaktsii $\mathrm{Fe}^{3+} / \mathrm{Fe}^{2+} \mathrm{v}$ rastvorakh solyanoi kisloty (Inhibition of the $\mathrm{Fe}^{3+} / \mathrm{Fe}^{2+}$ reaction in hydrochloric acid solutions), in Ingibitory korrozii metallov (Metal Corrosion Inhibitors), Ed.: S.A. Balezin, Moscow, MGPI im. V.I. Lenina, 1979, 37-43 (in Russian).

113. V.D. Fateev, S.A. Balezin and N.G. Klyuchnikov, Podbor i issledovanie ingibitorov korrozii kotel'nykh stalei v rastvorakh limonnoi kisloty (Selection and study of corrosion inhibitors for boiler steels in citric acid solutions), in Ingibitory korrozii metallov. (Metal Corrosion Inhibitors.), Eds.: S.A. Balezin, F.B. Glilina, N.I. Podobaev, N.G. Klyuchnikov and E.G. Zak, Moscow, MGPI im. V.I. Lenina, 1969, 181-189 (in Russian).

114. L.I. Antropov and I.S. Pogrebova, Svyaz' mezhdu adsorbtsiei organicheskikh soedinenii i ikh vliyaniem na korroziyu metallov v kislykh sredakh (The relationship between the adsorption of organic compounds and their effect on the corrosion of metals in acidic environments), in Korroziya $i$ zashchita ot korrozii. T. 2. (Itogi nauki i tekhniki) (Corrosion and corrosion protection. V. 2. (Results of Science and Technology)), Moscow, VINITI, 1973, pp. 27-112 (in Russian).

115. Ya.G. Avdeev, M.V. Tyurina and Yu.I. Kuznetsov, Zashchita nizkouglerodistoi stali v rastvore fosfornoi kisloty ingibitorom IFKhAN-92. Ch. 3. Vliyaniye kationov zheleza (Protection of low carbon steel in a solution of phosphoric acid by IFKhAN-92 inhibitor. Part 3. The effect of iron cations), Korroz.: Mater., Zashch. (Corrosion: Materials, Protection), 2014, no. 1, 18-25 (in Russian).

116. M.V. Tyurina, Zashchita nizkouglerodistoi stali $v$ rastvorakh fosfornoi kisloty proizvodnymi triazola (Protection of low-carbon steel in phosphoric acid solutions by triazole derivatives), Dissertatsiya kandidata khimicheskikh nauk (PhD Chemistry Dissertation), A.N. Frumkin Institute of Physical Chemistry and Electrochemistry, RAS, Moscow, 2016, 140 pp. (in Russian).

117. S.L.F.A. da Costa and S.M.L. Agostinho, Electrochemical Behavior of copper in $0.5 \mathrm{M}$ $\mathrm{H}_{2} \mathrm{SO}_{4}$ Solutions in the Absence and Presence of Fe(III) and Benzotriazole, Corrosion, 1989, 45, no. 6, 472-477. doi: $10.5006 / 1.3582046$ 
118. O. Sisso, S. Dor, D. Eliyahu, E. Sabatani and N. Eliaz, Corrosion inhibition of copper in ferric chloride solutions with organic inhibitors, npj Mater. Degrad., 2020, 4, no. 38, 116. doi: $10.1038 / \mathrm{s} 41529-020-00139-0$

119. Ya.G. Avdeev, O.A. Kireeva, D.S. Kuznetsov and Yu.I. Kuznetsov, The Influence of Hexamethylenetetramine on the Corrosion Inhibition of Low Carbon Steel in Mixtures of Sulfurous and Phosphorus Acids Containing Fe(III) by IFKhAN-92 and KNCS Composition, Prot. Met. Phys. Chem. Surf., 2018, 54, no. 7, 1298-1304. doi: $\underline{10.1134 / \mathrm{S} 2070205118070055}$

120.Ya.G. Avdeev, O.A. Kireeva, D.S. Kuznetsov and Yu.I. Kuznetsov, Usilenie urotropinom ingibirovaniya korrozii stali 08PS kompozitsiei IFKhAN-92 s KNCS v smesyakh $\mathrm{HCl}$ i $\mathrm{H}_{3} \mathrm{PO}_{4}$, soderzhashchikh $\mathrm{Fe}$ (III) (Improvement of corrosion inhibition of steel 08PS by composition of IFKhAN-92 with KNCS in mixtures of $\mathrm{HCl}$ and $\mathrm{H}_{3} \mathrm{PO}_{4}$ containing Fe(III) by urotropine), Korroz.: Mater., Zashch. (Corrosion: Materials, Protection), 2018, no. 7, 22-28 (in Russian). doi: 10.31044/1813-7016-2018-0-7-22-28

121. Ya.G. Avdeev, T.E. Andreeva and A.V. Panova, Effect of urotropine on the potential of the $\mathrm{Fe}(\mathrm{III}) / \mathrm{Fe}(\mathrm{II})$ redox couple in mineral acid solutions, Int. J. Corros. Scale Inhib., 2020, 9, no. 2, 571-583. doi: 10.17675/2305-6894-2020-9-2-12

122. S.A. Balezin, F.B. Glilina and I.S. Mikhal'chenko, Kinetika rastvoreniya stali $10 \mathrm{v}$ ingibirovannykh rastvorakh trilona B (Dissolution kinetics of steel 10 in inhibited solutions of Trilon B), in Ingibitory korrozii metallov (Metal Corrosion Inhibitors), Eds.: S.A. Balezin, E.G. Zak, F.B. Glilina, N.I. Podobaev and N.G. Klyuchnikov, Moscow, MGPI im. V.I. Lenina, 1972, 31-43 (in Russian). 